Cómo citar este trabajo: Ruano de la Fuente, J. M., Iglesias Jiménez, E., \& Polo Villar, C. (2019). El Madrid vivido: los problemas urbanos desde la perspectiva de la ciudadanía en el contexto del turismo de masas. Boletín de la Asociación de Geógrafos Españoles, 83, 2826, 1-38. http://dx.doi.org/10.21138/bage.2826

\title{
El Madrid vivido: los problemas urbanos desde la perspectiva de la ciudadanía en el contexto del turismo de masas
}

Lived Madrid: urban problems from the citizens' perspective in the context of mass tourism

José Manuel Ruano de la Fuente

jmruanof@ucm.es

Departamento de Ciencia Política y de la Administración

Universidad Complutense de Madrid (España)

Eduardo Iglesias Jiménez

eiglejim@uax.es

Área de Ciencias de la Salud

Universidad Alfonso X El Sabio (España)

\section{César Polo Villar}

polo@cps.ucm.es

Departamento de Ciencia Política y de la Administración

Universidad Complutense de Madrid (España)

\section{Resumen}

El artículo analiza los problemas del distrito Centro de Madrid desde la perspectiva de sus habitantes. Partiendo de la presentación de las principales características demográficas y 
territoriales del distrito y del análisis de los instrumentos de intervención impulsados desde el Ayuntamiento, se identifican posteriormente los principales problemas sentidos por la población a partir de los datos contenidos en los espacios formales de participación ciudadana y de las entrevistas mantenidas con representantes de asociaciones de vecinos, técnicos municipales, concejales e individuos no organizados. El trabajo muestra, desde la perspectiva de los ciudadanos, que el turismo no es percibido como uno de los principales problemas del distrito Centro, aunque sí lo son otros fenómenos asociados a él.

Palabras clave: turismo; centros urbanos; turismofobia; participación ciudadana; gestión urbana.

\begin{abstract}
The article analyses the problems of the central district of Madrid from the perspective of its inhabitants. Based on the presentation of the main demographic and territorial features of the district and on the study of the instruments of intervention promoted by the City Council, the main problems felt by the population are subsequently inferred from the data contained in the formal rooms of citizen participation and from the interviews held with representatives of neighbourhood associations, municipal staff, city councillors and non-organised individuals. The research shows, from the citizens' perspective, that tourism is not perceived as one of the main problems of the Central District, but other phenomena linked to it.
\end{abstract}

Key words: tourism; urban centers; tourismphobia; citizen participation; urban management.

\title{
1 Introducción
}

Si el territorio urbano es a un tiempo producto y escenario de múltiples interacciones entre actores sociales e institucionales, el centro de la ciudad se revela como espacio de convivencia e integración a la vez que condensa todos los malestares que aquejan a las ciudades. La emergencia y la intensificación del turismo de masas durante los últimos años ha (re)significado la relación de la ciudadanía con el espacio público, ha transformado el paisaje comercial tradicional, ha reducido la oferta de vivienda residencial y ha alterado las relaciones interpersonales amenazando al cabo con la pérdida de identidad social y cultural del centro histórico y con la ruptura del tejido social tradicional, haciendo emerger nuevas tensiones entre los derechos de los moradores y los intereses de los agentes del mercado turístico.

Este trabajo no pretende elaborar un diagnóstico técnico más sobre la problemática del centro urbano, sino desvelar el "malestar urbano" desde la perspectiva de sus habitantes para ponerlo en 
correspondencia con la política institucional aplicada en el territorio. Concretamente, desde un enfoque multidisciplinar que combina miradas y métodos de la ciencia política y de la antropología aplicados al espacio urbano, se pretende identificar los principales problemas vividos y expresados por los habitantes del centro de la ciudad de Madrid en tres dimensiones de análisis:

a) un enfoque macro que contempla las acciones y proyectos del Ayuntamiento de Madrid para el distrito Centro en materia de turismo y, sobre todo, del impacto de este sector económico en la configuración espacial del entorno y de la vida social;

b) desde una perspectiva de análisis intermedio se pretende conocer y analizar la voz de los ciudadanos organizados y activos en los espacios institucionales reservados a la participación vecinal; y

c) desde un enfoque de microanálisis, se intenta detectar y describir las vivencias de los ciudadanos individuales no organizados y de los nuevos movimientos y organizaciones sociales que operan en los márgenes de las estructuras institucionales para complejizar las posiciones y equilibrar los discursos de los representantes institucionales.

En esencia, el objetivo de este trabajo consiste en verificar hasta qué punto las intervenciones del gobierno municipal sobre el territorio incorporan referencias a los impactos generados por el turismo en la ciudad y contemplan, en los planes en los que esas actuaciones se materializan, las demandas de la ciudadanía adoptando un enfoque integral. El marco temporal de análisis es el período 2015-2019, que corresponde con el mandato de la alcaldesa Manuela Carmena. Ahora bien, debe tenerse en cuenta que algunos de los planes de intervención analizados (planes de barrio o planes de intervención turística) trascienden el período electoral estricto en la medida en que pueden haber sido aprobados con anterioridad, aun cuando dejan sentir sus efectos en la ciudad mientras no sean modificados o derogados. Análogamente, algunos de los espacios de participación ciudadana se analizan lógicamente desde el momento de su creación (singularmente, el Foro Local, que sustituye al Consejo Territorial desde 2017). Así mismo, se han analizado las bases de datos de quejas y sugerencias presentadas en el distrito disponibles en el portal de datos abiertos del Ayuntamiento de Madrid, las cuales, si bien no abarcan todo el período de mandato, conforman una enorme base muestral de la totalidad de las quejas expresadas en él.

El plan de exposición del trabajo es el siguiente: en primer lugar, se expondrá la metodología utilizada y las principales líneas teóricas en las que se enmarca la investigación; a continuación, se analizan los planes municipales del Ayuntamiento de Madrid haciendo especial hincapié en las acciones dirigidas al centro urbano y sus efectos esperados; en tercer lugar, se identifican los 
principales problemas del centro de Madrid a partir de la información extraída de las herramientas de participación del Ayuntamiento, tanto presenciales como digitales; y, todo ello se contrasta con la voz de la ciudadanía no organizada, cuya voz no se expresa a través de los canales institucionales formales, pero que permiten completar el relato completo del malestar de la vida en la ciudad.

\section{Metodología}

La metodología utilizada, necesariamente integradora de esta mirada interdisciplinar, combina herramientas de obtención de información propias del análisis de políticas públicas con instrumentos de carácter etnográfico en el nivel de microanálisis. El ámbito temporal del estudio comprende, a efectos de la recogida y análisis de la información documental, el último período de mandato municipal transcurrido entre los años 2015 y 2019.

En primer lugar, se ha recogido y analizado toda la información documental disponible sobre planes, programas operativos y proyectos del Ayuntamiento de Madrid dirigidos específicamente al distrito Centro de la ciudad con la finalidad de conocer en detalle sus líneas estratégicas, actividades y efectos e impactos esperados.

En segundo lugar, se ha realizado un inventario de los principales actores sociales del distrito y se ha extraído para su análisis toda la información cuantitativa contenida en la plataforma web Decide Madrid correspondiente al período de gobierno 2015-2019 así como las actas de las reuniones del Pleno y del Foro Local del Distrito Centro correspondientes al mismo espacio temporal. Se han obviado las propuestas tratadas en los Consejos territoriales desde 2015 hasta su desaparición en 2017 porque, al ser diferente su composición de la propia del Foro local y tener en ellos las asociaciones vecinales un peso mayor, podría ofrecer resultados distorsionadores.

Seguidamente se han analizado las bases de datos sobre quejas y sugerencias presentadas durante los años 2017, 2018 y hasta el mes de mayo de 2019, que son todas las disponibles en el portal de datos abiertos del Ayuntamiento de Madrid. Se trata de un volumen de 186339 quejas y sugerencias presentadas durante esos dos años y medio. De ellas, se han extraído las correspondientes al distrito Centro (10274) y se han categorizado para su mejor análisis y contraste con los resultados de las demás fuentes de información utilizadas. A continuación, el análisis de esta información cuantitativa se ha contrastado con la realización de 11 entrevistas en profundidad semiestructuradas realizadas durante el mes de mayo de 2019 a representantes de los cuatro grupos políticos del Ayuntamiento (incluido el concejal-presidente del Distrito), de 
asociaciones vecinales y de técnicos de participación ciudadana del propio Ayuntamiento. De este modo, se pretende poner en correspondencia los datos empíricos con la visión subjetiva expresada por los tres conjuntos de actores institucionales clave: políticos, técnicos y tejido asociativo.

En tercer lugar, se ha realizado trabajo de campo antropológico en el huerto de la Cornisa del barrio de la Latina y en las plazas de Nelson Mandela del barrio de Lavapiés, y Vara del Rey y Cascorro de la zona del Rastro. Se ha convivido con grupos sociales no representados en espacios participativos y se ha rescatado la mirada de sujetos individuales seleccionados por su disidencia no contemplada en los discursos institucionales, de tal forma que la información obtenida a pie de campo pueda ser contrastada con el análisis de ocho entrevistas escogidas abiertas de carácter etnográfico que permitan descubrir otras lógicas de convivencia a incorporar. El objetivo ha pasado por dar toda la potencia a las técnicas etnográficas con la idea de Identificar y alumbrar los individuos y grupos no contemplados en los estudios estratégicos para evaluar también el impacto que el turismo del distrito Centro tiene sobre sus vidas. En definitiva, promover una propuesta de trabajo complementaria que contemple los intangibles que condicionan las vidas de estos individuos y grupos en futuros estudios, o en estudios de similares características en otras ciudades, con el objetivo de explorar la posibilidad de su compatibilidad con los procedimientos de visibilización de la política municipal y la garantía del derecho de acceso a la ciudad (Lefèbvre, 1978).

\section{El centro urbano y las relaciones entre autoridades y ciudadanía.}

La ciudad puede contemplarse como el fruto de un sistema complejo de interacciones humanas en un espacio público preciso (Abler et al., 1972). Por eso, las intervenciones públicas revisten una importancia especial al procurar y modificar los sentidos de pertenencia e identificación a partir de las relaciones que se establecen con el territorio pues, siguiendo a Augé (2009), el espacio social es una malla constituida por los puntos de encuentro en la interacción entre agentes, espacios entendidos como "lugares", que condensan las representaciones de los sentidos asignados por sus usuarios. En la dimensión física de ese espacio, que es producto y escenario a un tiempo de intercambios políticos, sociales, económicos y culturales, se encuentran actores de naturaleza diversa (administraciones, asociaciones, movimientos sociales, e iniciativas particulares...) que participan de la generación de normas, acuerdos y costumbres con las que regular la convivencia (Duch, 2002). 
Quizá el ejemplo más evidente de la relación entre espacio y sociedad sea el "centro urbano", esa fracción de la ciudad que condensa una multitud de expresiones simbólicas y materiales. Así, el centro urbano se afirma como representación de la evolución de la sociedad y como ámbito de integración, por lo que su centralidad no lo es solo desde un punto de vista físico, sino desde una perspectiva funcional: conserva características morfológicas propias al tiempo que proporcionan identidad propia a sus moradores y forjan relaciones de vecindad. Esta multifuncionalidad del centro urbano exige una visión desde las tensiones entre las realidades físicas estáticas y las realidades socioeconómicas cambiantes (Troitiño, 2003). En esta línea argumental, el centro urbano puede derivar hacia la segregación o hacia el mantenimiento de su centralidad como espacio integrador, y esto, en buena medida, dependerá del sentido y de la efectividad de la acción de las Administraciones públicas en el territorio. Por su parte, desde el enfoque geográfico, Borja (2003) expone cómo el centro urbano es parte esencial de la movilidad de las personas, de la organización de los servicios y de las empresas, de las relaciones sociales y de la percepción simbólica. Otros autores (Ríos 2001; Rogers et al., 1955) advierten de cómo los centros urbanos pueden deteriorarse por la saturación del tráfico, la privatización del espacio público y otros intereses particulares que son fruto del crecimiento desordenado, lo que conduce a cambios en las relaciones sociales y en la condición de ciudadanía. De este modo, el déficit de equipamientos públicos, la escasez de suelo, la especulación inmobiliaria y la apatía de las autoridades a la hora de afrontar los problemas de la ciudadanía puede dar lugar a procesos caracterizados por la supeditación de las intervenciones públicas a los intereses económicos. Así, la intensificación del turismo, conjugada con la ausencia de políticas sostenibles, puede terminar impactando en el desarrollo urbanístico de la ciudad y su ordenación territorial, en las condiciones ambientales del centro, en la evolución de las condiciones de acceso a la vivienda residencial en el cambio en la tipología de los comercios y en una profunda transformación de la vida pública y privada ciudadana mediante nuevos usos y representaciones de los espacios. En este sentido, la sostenibilidad del turismo enlaza con el Programa de las Naciones Unidas para el Desarrollo, en cuyo objetivo 11 se señala la necesidad de que "las ciudades y los asentamientos humanos sean inclusivos, seguros, resilientes y sostenibles". Del mismo modo, la Organización Mundial del Turismo (2018) habla de "sobreturismo" para aludir al impacto negativo del turismo en la vida de los residentes, lo que depende no solo de la capacidad de los territorios para asumir un número determinado de visitantes ("capacidad de carga"), sino igualmente de las acciones de los poderes públicos para gestionarlo adecuadamente, por lo que propone como posibles soluciones el 
desarrollo de focos de atracción alternativos y diagnósticos certeros basados en indicadores cuantitativos y cualitativos.

Con todo, es incuestionable la participación en el empeño transformador de los actores que conforman la ciudad (Ruano, 2019). En esta línea argumental, los defensores de la democracia participativa argumentan que la deliberación y la adopción de decisiones entre los actores urbanos contribuyen a la mejora de la democracia, la efectividad y la transparencia del sistema político (Klausen \& Sweeting, 2005, Falleth et al., 2010). Concretamente, al enfrentarse a problemas complejos, los gobiernos municipales deben asegurarse de que sus propuestas se fundamentan en las experiencias de la ciudadanía. Los proyectos de desarrollo urbano comportan conflictos de intereses entre actores sociales, por lo que aquellos que abogan por fórmulas de intervención colaborativa o participativa las proponen como la mejor manera de equilibrar capacidad de gobierno y representatividad. (Innes \& Booher, 2003; Newig et al. 2005). Además, en los últimos años, se emplean cada vez más medios digitales como herramientas de comunicación entre los gobiernos y los ciudadanos, por lo que resulta interesante conocer cómo evoluciona su uso y de qué forma los gobiernos tratan de superar las asimetrías de poder y el conflicto de intereses entre actores sociales. No cabe desconocer sin embargo que la hipótesis de que las estrategias participativas mejoran la capacidad de respuesta de los gobiernos está lejos de ser verificada (Skelcher et al., 2011; Ruano, 2010). Bien al contrario, algunos trabajos analizan cómo algunas experiencias de democracia participativa pueden poner en riesgo a la democracia representativa (Hertting \& Klijn, 2018) o pueden desafiar las reglas y las formas habituales de trabajo de los empleados públicos (Agger \& Damgaard, 2018).

\section{Los planes de intervención territorial del Ayuntamiento de Madrid}

\subsection{Los Planes de Barrio}

Los Planes de Barrio surgen como instrumentos de intervención pública destinados a paliar o eliminar determinados desequilibrios territoriales entre los distintos barrios y zonas de Madrid. Sus orígenes se remontan a 2008 mediante un convenio firmado entre el Ayuntamiento de Madrid y la Federación Regional de Asociaciones de Vecinos de Madrid (FRAVM). Ambas instituciones seleccionan de manera consensuada los barrios o ámbitos de actuación prioritarios (distritos, barrios y zonas específicas de la Ciudad) en los que se diseñarán y pondrán en marcha los Planes de Barrio con la participación de los vecinos. 
Los ámbitos de actuación se establecen mediante la realización de un análisis estadístico de la estructura socioeconómica de las secciones censales de la ciudad, contrastándolo con los vecinos de cada uno de los barrios, tanto naturales como administrativos, y teniendo en cuenta indicadores como la tasa de desempleo, tasa de población sin estudios, tasa de senilidad, tasa de delincuencia, tasa de hacinamiento y la proporción de viviendas en mal estado; así como factores como la renta disponible bruta per cápita, los precios de la vivienda y la tasa de inmigración (Ayuntamiento de Madrid, 2019f)

Una vez consensuados los barrios en los que se actuará, el Ayuntamiento concierta con las asociaciones vecinales los Planes de Barrio correspondientes, en un proceso en el que las asociaciones proponen los contenidos que estiman prioritarios y el Ayuntamiento realiza un estudio de viabilidad técnica de cada una de las propuestas. En este sentido, los Planes de Barrio tienen una vocación participativa que se extiende igualmente a la ejecución, seguimiento y evaluación de las actuaciones, mediante el establecimiento de Comisiones Ciudadanas de Seguimiento en las que participa el Distrito, la FRAVM, las asociaciones vecinales de barrio y el Ayuntamiento de Madrid.

Los Planes Integrales de Barrio son una reconfiguración de los tradicionales Planes de Barrio que se realizan a partir de 2016, cuando pasan a financiarse a través del nuevo Fondo de Reequilibrio Territorial, creado con la finalidad de combatir el desequilibrio territorial de Madrid a través de acciones igualmente concertadas con las asociaciones vecinales, con 5 ejes prioritarios de actuación en los distritos de Madrid: empleo, vivienda, mejora y adecuación del entorno urbano, dotaciones y equipamientos, así como intervención y dinamización social.

Por su parte, el Estudio PIBA 2019 I (Ayuntamiento de Madrid, 2019g) ofrece una descripción pormenorizada de la metodología y los indicadores sociodemográficos utilizados para conocer la realidad social de los barrios incluidos en los Planes Integrales de Barrio (PIBA) y definir el grado de vulnerabilidad de los barrios de la ciudad.

Los planes de barrio y los planes integrales de barrio persiguen objetivos muy concretos en relación con los desequilibrios territoriales de la ciudad. Resulta llamativo que, en el caso de los planes de los barrios del Distrito Centro, no hemos encontrado ningún tipo de relación directa entre los objetivos y actuaciones que contemplan y la política turística de la ciudad de Madrid. Además, del análisis de los documentos estudiados tampoco se infieren las motivaciones de los proponentes de las actuaciones, en especial las que emanan de las asociaciones vecinales, y 
sobre si éstas desempeñan algún papel de relevante en la definición de los problemas derivados de la actividad turística en el distrito Centro.

\subsection{Los planes de intervención turística}

El sector turístico tiene una especial relevancia para la economía española por su peso sobre la economía y el empleo, tanto el que se crea directamente en actividades propias del sector como por su efecto arrastre o generación indirecta de empleo en otros sectores: por cada 100 empleos generados en las actividades características del turismo en contacto directo con el turista se generan 70,6 empleos en otros sectores de actividad de forma indirecta (EXCELTUR, 2018, p. 26). Esta característica del sector ha favorecido el despliegue de políticas que han centrado su atención casi exclusivamente en la generación de condiciones adecuadas para el crecimiento de la actividad turística y la satisfacción de los turistas.

El desarrollo del sector, propiciado igualmente por fenómenos convergentes como el abaratamiento de los transportes o, entre otros, el desarrollo de plataformas digitales de comercialización que han propiciado igualmente una reducción de los precios y la aparición de nuevas formas de alojamiento, ha generado una presión sobre los espacios urbanos que tiende a concentrarse en el centro de las ciudades, dando origen a determinados impactos o patologías que se identifican genéricamente con el término turistificación, en referencia a problemas como la presión sobre los servicios públicos, la desaparición del comercio tradicional, el deterioro de la convivencia o las molestias asociadas a la ocupación del espacio público, entre otros.

En el caso de la ciudad de Madrid, encontramos que la política turística no se ha definido en referencia a estos problemas y a otros posibles impactos del turismo, ya que no se reflejan en los planes y programas estratégicos de turismo de la ciudad. Tampoco aparecen en los diagnósticos que inspiran las propuestas que los actores políticos han presentado en las contiendas electorales de la ciudad en los últimos diez años ni son percibidos por los ciudadanos como efectos perniciosos generados por la actividad turística en la ciudad. Sólo muy recientemente se ha empezado a tener en cuenta estas conexiones, aunque con escasa incidencia en el diseño de la política turística de la ciudad.

Redactado sin referencia alguna a los temas que dominan la agenda pública de la ciudad, los objetivos, líneas estratégicas y planes de acción del PET 2008-2011 se centraron exclusivamente en el turista y en los intereses del sector turístico, y nos presenta una ciudad percibida como un activo que hay que poner en valor, "sacarle todo el partido", aunque, al mismo tiempo, se 
desdeña la posible incidencia del plan sobre los distritos y barrios de la ciudad, en especial del distrito Centro, en el que se concentra la actividad turística de la ciudad.

Por su parte, el Plan Estratégico de Turismo 2012-2015 es una continuación e intensificación de los objetivos y líneas estratégicas marcadas por el plan anterior, con una visión de la ciudad que se construye casi exclusivamente con la mirada de los actores centrales del sector turístico, tal y como se declara expresamente en el mismo documento. Se conforma así un diagnóstico que sólo representa los intereses del sector y centra su análisis exclusivamente en el potencial de crecimiento de la actividad turística de la ciudad de Madrid (Ayuntamiento de Madrid, 2012, pp. 22-107). Sin embargo, la elaboración del plan se presenta en el documento como una "propuesta abierta y participativa" (Ayuntamiento de Madrid, 2012, p. 16), conceptos que, sin embargo, en su desarrollo sólo alcanzan a explorar "la percepción que de la ciudad de Madrid tienen los profesionales del turismo y los turistas, tanto nacionales como extranjeros" (Ayuntamiento de Madrid, 2012, p. 18).

Del mismo modo, y en consonancia con el concepto de identidad de la Ciudad que se realizaba en el PET 2008-2011, en el que se describía a Madrid como una "ciudad abierta, hospitalaria y multicultural", el PET 2012-2015 parece aspirar a configurar un modelo de ciudad en el que la percepción y los intereses de turistas y residentes habituales se fusionen (Ayuntamiento de Madrid, 2012, p. 4). Es así como el plan renuncia expresamente a integrar una visión holística y más plural de la ciudad, que incorpore la mirada, intereses y demandas de sus habitantes con sus necesidades específicas, que complemente e informe la racionalidad con la que se establecen los objetivos, líneas estratégicas y planes de actuación. En la misma línea, el Plan Estratégico Madrid Destino (2015-2019) mantiene los objetivos estratégicos definidos en los planes anteriores, basados en la desestacionalización de la actividad turística y en la mejora de la calidad de los servicios. En ningún caso se hace mención a los problemas que se asocian al turismo de masas o a variables de sostenibilidad para definir los objetivos estratégicos y las líneas estratégicas o iniciativas de actuación.

Del mismo modo, la revisión de los planes y programas de intervención municipal en el distrito permite constatar la prevalencia de una mirada sectorial en su diseño, sean éstos estratégicos u operativos, y la ausencia de un diagnóstico integral que permita identificar las conexiones de esos problemas con el turismo o con otros problemas de la ciudad.

Ni siquiera el Plan de Gobierno 2015-2019 establece líneas estratégicas orientadas a ordenar la dispersión sectorial conectando problemas y señalando líneas de actuación en referencia a las 
causas que los originan. De esta forma, este plan, del que se podía esperar una mirada holística e integral de los problemas de la ciudad, básicamente muestra un sumario o compendio de los planes de actuación sectorial que ejecutan las distintas áreas de gobierno, organizados por "ejes estratégicos" que, en el caso del turismo, mayormente hacen referencia explícita a los objetivos estratégicos y líneas de actuación ya incluidos en los planes estratégicos de turismo o en otros planes, identificando el área de gobierno u organización municipal encargada de su impulso y ejecución.

\subsection{La primera percepción sobre los efectos negativos del turismo}

En Mayo de 2017 se presentó el estudio "Análisis del Impacto de las viviendas de uso turístico (VUT) en el Distrito Centro de Madrid", realizado por la Entidad Red2Red Consultores como consecuencia de una petición explícita por parte de la Junta Municipal de Distrito Centro, tras recibir numerosas interpelaciones tanto por parte de los empresarios del sector hostelero, que se quejaba de su desprotección ante el fenómeno de la proliferación de las viviendas de uso turístico (VUT), como por parte de los vecinos que pensaban que el espacio público parecía estar más dispuesto a las necesidades de visitantes y transeúntes que a las propias de los residentes del distrito (Ayuntamiento de Madrid, 2017, p. 21). El estudio tenía por objeto realizar una investigación de campo de la evolución de este tipo de viviendas en el distrito Centro, con la finalidad de aportar información útil al Ayuntamiento para afrontar el reto de gestionar el turismo ante las claras previsiones de crecimiento del sector para los siguientes años.

A este respecto, se enumeraban una serie de factores de riesgo que podían incidir negativamente sobre el distrito y su población en el caso de una oferta descontrolada de VUT, profundizando en los fenómenos de gentrificación y turistificación con los que ya se caracteriza al distrito Centro, como el impacto en el mercado inmobiliario, el deterioro de la convivencia vecinal, el impacto en el comercio, la emergencia de un nuevo modelo de turismo y, en fin, la competencia desleal de estas actividades y su fiscalidad (Ayuntamiento de Madrid, 2017, p. 22).

El estudio arroja algunos datos y conclusiones interesantes para este trabajo, entre los que destaca la consideración mayoritaria y compartida por la mayor parte de los informantes consultados de que el "fenómeno del "cambio de fisonomía" del Centro de Madrid y la masificación y saturación son debidas a diversos fenómenos convergentes, entre los que hay que considerar "la apuesta política continuada por un determinado modelo de ciudad" (Ayuntamiento de Madrid, 2017, p. 41) y "la progresiva especialización comercial y de tránsito del centro" (Ayuntamiento de Madrid, 2017, p. 65); concluyendo que las VUT se convierten así en causa y consecuencia del 
fenómeno de la turistificación. Así, el turismo se advierte como un factor adicional que alimenta la complejidad del fenómeno urbano, que contiene elementos negativos, pero también consecuencias positivas "para los usuarios, los ciudadanos y la economía de las ciudades", tal como destaca el informe de la Comisión Nacional de los Mercados y de la Competencia de julio de 2018 (CNMC, 2018, p. 16), en la medida en que las viviendas de uso turístico favorecen la competencia en el sector, contribuyen a un uso más eficiente de los espacios urbanos y a la modernización de los barrios degradados y dinamizan la economía. En este sentido, el estudio denuncia una actividad regulatoria de las VUT excesiva y muy dispar entre ciudades y comunidades autónomas, que "con frecuencia, restringen la oferta y la capacidad de competir de las VUT y, por ello, son perjudiciales para consumidores, ciudadanos y para la economía en su conjunto" (CNMC, 2018, p. 62).

Más allá de esta controversia sobre los efectos del turismo de masas, lo cierto es que el Ayuntamiento de Madrid, consciente ya de los efectos negativos del sector sobre el territorio, aprobó al final del período de mandato 2015-2019 el "Plan de Regulación del uso de servicios terciarios en la clase de hospedaje", que ejemplifica perfectamente el tipo de iniciativas de regulación restrictiva a las que alude la CNMC, ya que tiene por objeto frenar la conversión de viviendas residenciales del Centro de la ciudad en VUT y otros alojamientos turísticos mediante la obligación de solicitud de una licencia de uso terciario de hospedaje cuando se alquilen para uso turístico, la presentación de un estudio de impacto en el entorno cuando se pretenda convertir un edificio completo de uso residencial en un hotel u otro establecimiento similar, y la exigencia a los nuevos alojamientos turísticos de contar con un acceso independiente cuando compartan edificio con otras viviendas de uso residencial. En todo caso, como veremos más adelante, la iniciativa del gobierno municipal, de recorrido incierto por la complejidad intergubernamental del problema y la variedad de intereses contradictorios, llegó tarde para enfrentar un problema que venía gestándose desde hace años.

\section{La voz de la ciudadanía organizada}

\subsection{Particularidades sociodemográficas para el análisis del distrito}

Antes de pasar a analizar los espacios formales de expresión de las demandas de los ciudadanos del distrito, conviene tener en cuenta algunos rasgos que hacen de él un ámbito territorial que cuenta con unas características sociales y demográficas especiales en comparación con los demás distritos de la ciudad. 
Así, según el censo de población a fecha de 1 de enero de 2018, Madrid tiene 3221824 habitantes, de los que 132352 (el 4,10\%) viven en los 5,2 kilómetros cuadrados del distrito Centro. Se trata del distrito de Madrid (de los 21 en que se divide su territorio) más densamente poblado con 253 habitantes por hectárea, aunque el número de niños se reduce progresivamente. Concretamente, el año 2011 fue el primero de este siglo en el que el número de niños del distrito menores de cinco años cayó por debajo de los 5000. En solo siete años, se ha pasado a menos de 4000 (3988 exactamente en 2018). El escaso número de niños que vive en el distrito se debe, por un lado, a la tasa de natalidad más baja de toda la ciudad (9,00 en todo Madrid frente a 7,32 en el distrito Centro), unido a la tasa general de fecundidad más baja de la ciudad (37,91 frente a 27,86 nacimientos por cada 1000 mujeres entre 15 y 49 años) y a una tasa de crecimiento vegetativo negativo $(-0,61$ frente al 0,55 de toda la ciudad). Sin embargo, en los seis barrios que conforman el distrito Centro, el número de habitantes que tienen entre 25 y 39 años es de los más altas de Madrid (41021 personas), lo que parece indicar que las familias se mueven a otras partes de la ciudad y son reemplazadas por jóvenes, como muestra el hecho de que el número de nacimientos sea mayor en la periferia que en el centro (Ayuntamiento de Madrid, 2019a).

La composición social del distrito presenta también otros rasgos particulares: el distrito Centro es el que presenta el mayor número de personas que viven solas (32234, esto es, el 24,35\%), así como el número mayor de ciudadanos nacidos fuera de España, que alcanza el 30,77\% del total. Por último, interesa subrayar que el distrito Centro cuenta con el mayor tejido asociativo de la ciudad representado en la existencia de 264 asociaciones registradas, mientras que el segundo distrito con mayor número de asociaciones es Puente de Vallecas, que presenta 162 (Ayuntamiento de Madrid, 2019a).

\subsection{La identificación de problemas a través de los canales de participación ciudadana}

El distrito es el ámbito territorial de la participación ciudadana. Madrid divide su territorio en 21 distritos que, a su vez, se subdividen en 128 barrios. En el órgano de gobierno de esta institución de gestión desconcentrada de la ciudad de Madrid (Junta Municipal del Distrito) están representados los concejales o los vocales-vecinos (vecinos del distrito nombrados a propuesta de los grupos políticos municipales) en proporción a la representación obtenida en las elecciones municipales. Así, el Pleno del distrito toma decisiones y realiza propuestas al área de gobierno correspondiente sobre los problemas que afectan a este ámbito territorial. Los órganos de participación ciudadana en el distrito son los Consejos sectoriales, el Consejo Director de la Ciudad y los Foros locales. Los consejos sectoriales son órganos consultivos especializados en los 
diferentes ámbitos de actuación del gobierno municipal, mientras que el Consejo Director se configuró como un espacio general de reflexión estratégica sobre la ciudad. Sin embargo, la novedad en materia de participación ciudadana fue la creación en 2017 de los Foros locales en cada uno de los distritos como un ámbito de participación en que es posible la adopción de acuerdos y la presentación de iniciativas al Pleno del distrito sobre cualquier asunto por parte de ciudadanos individuales mayores de 16 años (el derecho al voto en la legislación general lo tienen los ciudadanos mayores de 18) y de entidades ciudadanas registradas en el Ayuntamiento. La creación de los Foros locales supuso la desaparición de los Consejos territoriales, en los que la participación ciudadana estaba protagonizada por las asociaciones de vecinos (Ruano, 2010). A partir de la creación de los Foros, el poder de las asociaciones empezó a diluirse frente al ciudadano no asociado, si bien siguen conservando un mayor número de votos (entre 2 y 6) según el número de los miembros a los que representa. Así, el Pleno del distrito toma decisiones sobre los asuntos que afectan a este territorio, pero también recibe propuestas de actuación para su deliberación y aprobación en su caso, procedentes de los Foros locales y de las asociaciones de vecinos.

Otra de las grandes novedades del modelo de participación ciudadana puesto en práctica en Madrid durante el período 2015-2019 fue el desarrollo de la plataforma web "Decide Madrid". Esta web cumple una triple función: como espacio de deliberación, en la medida en que los ciudadanos pueden debatir sobre diversos asuntos que afectan a la ciudad; como espacio para la presentación de propuestas, que pasan a ser votadas cuando son apoyadas por el $1 \%$ de las personas mayores de 16 años empadronadas en la ciudad (concretamente, 27064) o cuando el propio Ayuntamiento somete un tema a votación (en 2017 el Ayuntamiento sometió a votación la reforma de la Gran Vía, Plaza de España y la remodelación de espacios públicos en 11 distritos de Madrid, y dos propuestas en materia ambiental y de movilidad: "Madrid 100\% sostenible" y "Billete único para el transporte público"); y, por último, como espacio para la decisión sobre el destino de una parte del presupuesto municipal a través de un proceso que se divide en varias fases: presentación de proyectos, recogida de apoyos populares, análisis técnico sobre su viabilidad, competencia municipal y costes, y votación final. Los presupuestos participativos están dotados con 100 millones de euros durante los tres últimos años (70 millones en 2016), de los que el $70 \%$ se destina a los distritos y el $30 \%$ a proyectos para toda la ciudad. El reparto de esa cantidad de dinero entre los 21 distritos es directamente proporcional al número de habitantes e inversamente proporcional a la renta per cápita. Debe subrayarse que el modelo participativo de la ciudad de Madrid es un modelo innovador en la medida en que combina espacios de 
participación presenciales (Pleno del Distrito, Foros locales) y digitales (web Decide Madrid), y en el que los resultados de las consultas y de los presupuestos participativos son asumidos como vinculantes para el gobierno de la ciudad.

Así, al distrito Centro le correspondió en 2016 1,4 millones de euros, y casi 2,5 millones en 2017, 2018 y 2019, lo que supone aproximadamente el 33 \% de todas las inversiones programadas en el distrito en 2019. En los tres primeros años, que son los únicos en los que se han votado los proyectos de gasto asociados a los presupuestos participativos, la participación se situó en unas cifras modestas: entre el 3,30 y el 3,97\% de la población mayor de 16 años empadronada en el distrito (ver Figura 1).

Figura 1. Participación en presupuestos participativos de ciudadanos del distrito Centro

\begin{tabular}{|c|c|c|c|}
\hline Años & 2016 & 2017 & 2018 \\
\hline Total participantes & 3990 & 4793 & 4247 \\
\hline \% participación & 5,79 & 5,08 & 3,67 \\
\hline \% censo del distrito & 3,30 & 3,97 & 3,51 \\
\hline
\end{tabular}

Fuente: elaboración propia a partir de datos del portal web Decide Madrid

Finalmente, los proyectos aprobados en el distrito para el período 2016-2018 fueron 34, de entre los cuales la mayoría están relacionados con preocupaciones medioambientales o con la escasez de infraestructuras y equipamientos públicos (ver Figura 2). En la misma línea, de las 28 propuestas presentadas para la votación correspondiente a 2019, 23 tratan sobre mejora de infraestructuras físicas y 4 sobre aspectos medioambientales.

Consultado el personal técnico del Ayuntamiento por el modelo de presupuesto participativo, este reconoce como principales dificultades la falta de cultura ciudadana, que explicaría la escasa participación, y la falta de cultura administrativa, que se transforma en fuertes resistencias por parte de los funcionarios del Ayuntamiento: "en los presupuestos participativos hay que licitar los proyectos y ejecutarlos. Además, se trata de proyectos adicionales (algunos más concretos y otros más genéricos) que se suman a la carga de trabajo de los proyectos del Ayuntamiento, lo que ha provocado tensiones entre la Dirección General de Participación Ciudadana y las Áreas de Gobierno encargadas de implementar los proyectos" (Entrevista n 1). 
Figura 2. Tipo de proyectos aprobados mediante participación ciudadana en Distrito Centro (2016-2018)

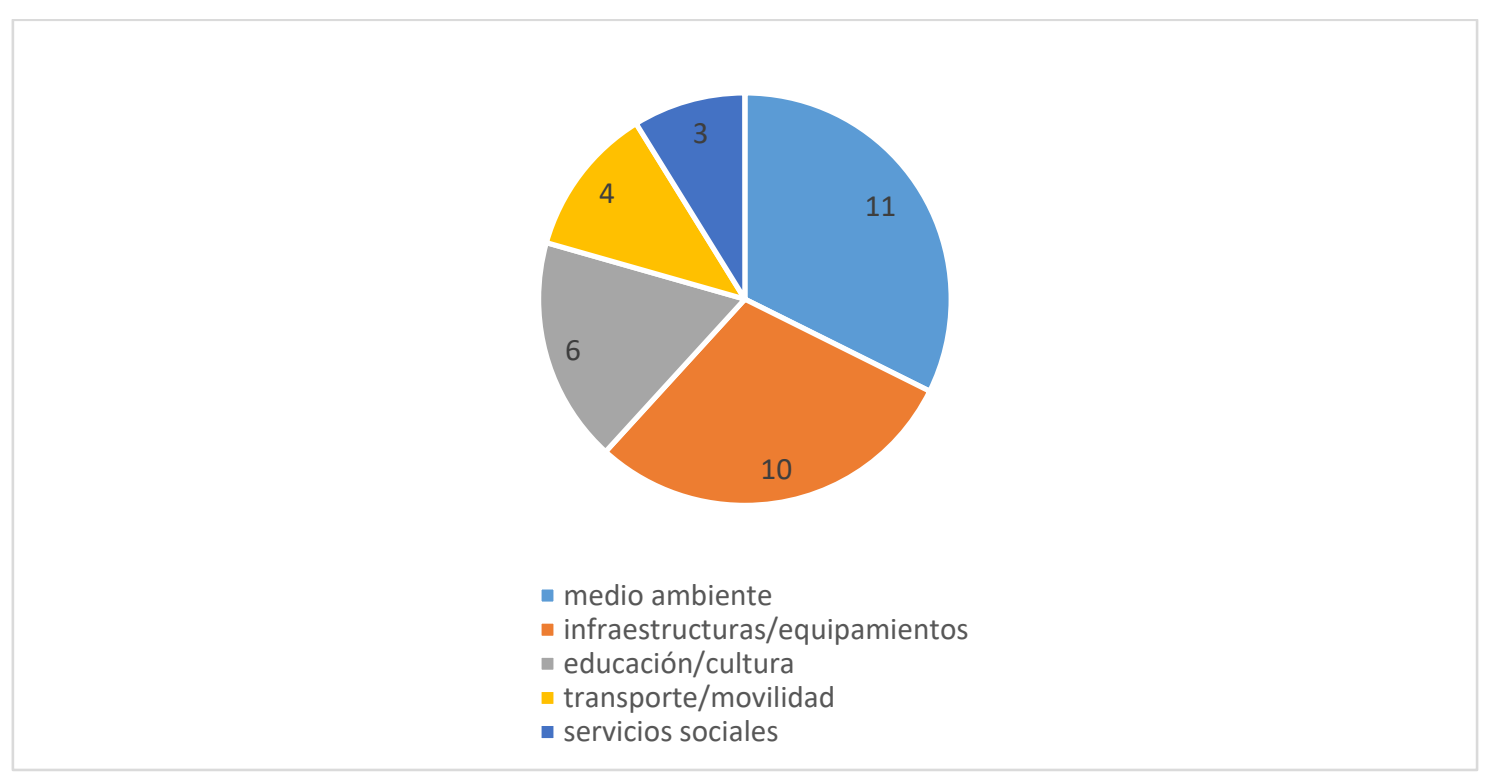

Fuente: elaboración propia a partir de datos del portal web Decide Madrid

Por otro lado, la puesta en marcha de herramientas digitales de participación no ha sustituido a los instrumentos presenciales ni la actividad de las asociaciones de vecinos del distrito. En este sentido, la Coordinadora de Asociaciones de Vecinos del Distrito Centro entregó a los cuatro partidos políticos con representación en el Ayuntamiento un documento de 195 puntos que presentaban los principales problemas del distrito y proponían medidas para su solución. Como puede verse en la Figura 3, los principales problemas pueden agruparse en la categoría de medio ambiente (ruido, suciedad, contaminación), movilidad (medidas de restricción del tráfico a la zona centro) y comercio, puesto que entienden que algunos de los principales problemas del distrito (singularmente, el ruido, la suciedad, el acceso de vehículos privados, la inseguridad o el incremento de los precios de la vivienda) tienen que ver con un modelo de ciudad concebida para el visitante ocasional y el turista, y que termina perjudicando al residente habitual y transformando radicalmente el modo de vida tradicional.

En cuanto a los espacios presenciales de participación, se han analizado todas las propuestas realizadas en el Distrito por parte de los concejales de los cuatro grupos políticos o por los vecinos designados por ellos (denominados vocales-vecinos). Se trata de 390 propuestas presentadas a lo largo de los cuatro años del período de mandato (2015-2019). Además, se suman a estas las propuestas elevadas por el Foro Local al Pleno del Distrito desde su creación en 2017 hasta el final del período. 
Figura 3. Grupos de problemas del Distrito identificados por las Asociaciones de vecinos

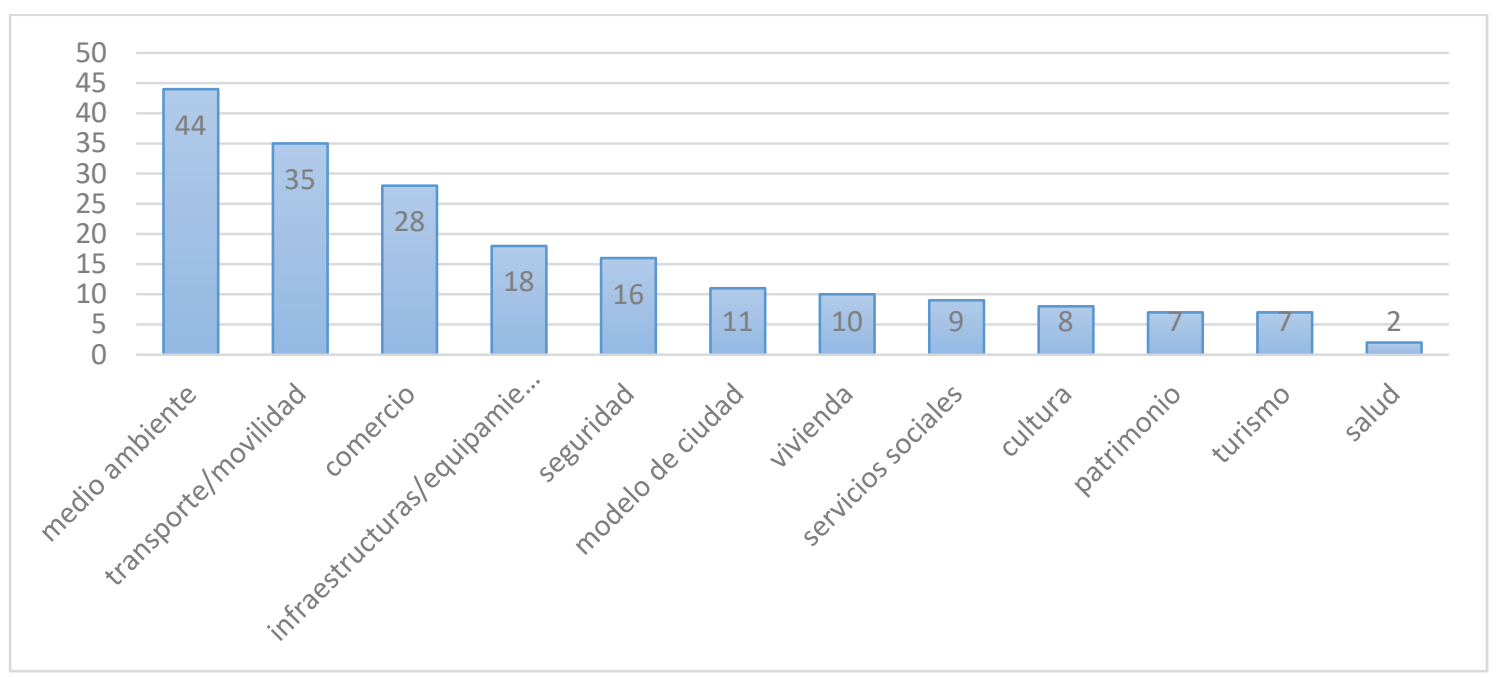

Fuente: elaboración propia a partir de la información proporcionada por la Coordinadora de Asociaciones de Vecinos Madrid Centro

Así, como se observa en la Figura 4, durante el período analizado la mayor parte de las propuestas presentadas en el Pleno del Distrito tienen que ver con la mejora de los espacios públicos y la demanda de equipamientos en el distrito, al tiempo que aparecen de nuevo las preocupaciones por la suciedad, la contaminación y los conflictos entre el uso del transporte privado y el público en el centro de la ciudad. Por lo que se refiere al Foro local, el número de propuestas elevadas al Pleno del Distrito es comparativamente mucho más modesto y, quizá por su organización interna en mesas temáticas, las propuestas se reparten entre temas más variados.

Si se contrastan los datos expresados en los ámbitos de participación con las "Encuestas de calidad de vida y satisfacción con los servicios públicos de la ciudad de Madrid" realizadas por el Ayuntamiento, resulta llamativo, por un lado, la persistencia en el tiempo de algunos de los problemas identificados; y, por otro, la mayor intensidad sentida por los ciudadanos de Centro de algunos problemas. Así, en las sucesivas encuestas del Ayuntamiento de Madrid, desde 2016 y hasta 2019 la falta de limpieza es el principal problema de la ciudad (señalado como tal por el $40 \%$ de los vecinos de la ciudad), mientras que la contaminación y el tráfico son el segundo y el tercer problema, respectivamente, desde 2017, en tanto que "el coste de la vivienda" aparece por primera vez, situado en cuarto lugar, en toda la serie de encuestas en 2019. Resulta significativo en todo caso que, para los ciudadanos del distrito Centro, los problemas sentidos con más intensidad que por el resto de conciudadanos sean la falta de limpieza (es el problema principal para el $42,7 \%$ ), el alto coste de la vivienda, el ruido, el aparcamiento público y la falta de parques infantiles (Ayuntamiento de Madrid, 2017b y 2019i). 
Figura 4. Propuestas presentadas en el Pleno del Distrito y el Foro Local

\begin{tabular}{|c|c|c|}
\hline Temas & $\begin{array}{c}\text { Pleno del } \\
\text { Distrito } \\
\text { 2015-2019 }\end{array}$ & $\begin{array}{l}\text { Foro Local } \\
2017-2019\end{array}$ \\
\hline $\begin{array}{l}\text { Infra estructuras y equipamientos } \\
\text { (obras públicas, construcciones, reformas,...) }\end{array}$ & 85 & 4 \\
\hline $\begin{array}{l}\text { Medio a mbiente } \\
\text { (contaminación atmosférica y acústica, limpieza, jardines, ...) }\end{array}$ & 51 & 4 \\
\hline $\begin{array}{l}\text { Transporte y movilidad } \\
\text { (líneas de autobuses y metro, zonas restringidas al tráfico, } \\
\text { aparcamientos, nuevas formas de movilidad,...) }\end{array}$ & 39 & 0 \\
\hline $\begin{array}{l}\text { Campañas de sensibiliza ción } \\
\text { (minorías étnicas, sexuales, inmigrantes, mujeres,...) }\end{array}$ & 37 & 4 \\
\hline $\begin{array}{l}\text { Administración pública } \\
\text { (transparencia, rendición de cuentas, información, } \\
\text { participación ciudadana,...) }\end{array}$ & 28 & 1 \\
\hline $\begin{array}{l}\text { Educación } \\
\text { (conservación de colegios y centros de mayores, planes de } \\
\text { educación cívica o sexual, actividades extraescolares,...) }\end{array}$ & 26 & 4 \\
\hline Cambios de nombres de calles y colocación de placas & 21 & 3 \\
\hline $\begin{array}{l}\text { Comercio } \\
\text { (licencias de actividad, terrazas, venta ambulante, ocio } \\
\text { nocturno,...) }\end{array}$ & 20 & 0 \\
\hline $\begin{array}{l}\text { Servicios sociales } \\
\text { (personas con discapacidad, ayudas sociales, inclusión } \\
\text { social, sinhogarismo, ...) }\end{array}$ & 20 & 1 \\
\hline $\begin{array}{l}\text { Seguridad } \\
\text { (actuación de la policía, tráfico de drogas, ...) }\end{array}$ & 17 & 0 \\
\hline $\begin{array}{l}\text { Cultura y patrimonio } \\
\text { (tradiciones, fiestas, exposiciones, conservación monumental, } \\
\text { conciertos,...) }\end{array}$ & 17 & 5 \\
\hline $\begin{array}{l}\text { Vivienda } \\
\text { (gentrificación, viviendas vacías, viviendas turísticas, } \\
\text { desahucios,...) }\end{array}$ & 10 & 2 \\
\hline $\begin{array}{l}\text { Salud } \\
\text { (salud sexual, plagas, campañas de prevención,... }\end{array}$ & 10 & 0 \\
\hline $\begin{array}{l}\text { Deportes } \\
\text { (actividades deportivas) }\end{array}$ & 4 & 0 \\
\hline $\begin{array}{l}\text { Empleo } \\
\text { (condiciones laborales de empleados del Ayuntamiento) }\end{array}$ & 3 & 0 \\
\hline $\begin{array}{l}\text { Turismo } \\
\text { (planes de turismo en la ciudad) }\end{array}$ & 2 & 0 \\
\hline TOTAL & 390 & 28 \\
\hline
\end{tabular}

Fuente: elaboración propia a partir de la información de las Actas de los Plenos del Distrito y del Foro Local

Uno de los problemas del Foro local, tal como se reconoce en algunas de sus actas, es la escasa participación general de la ciudadanía en las reuniones, y muy especialmente de los jóvenes, lo 
que quizá encuentra su explicación, tal como señalan los funcionarios del Ayuntamiento, en la falta del desarrollo de una cierta cultura participativa construida en base a una desconexión cada vez mayor entre instituciones y ciudadanía que parece requerir de algo más que este tipo de consultas masivas a la población. Siendo más incisivos, es precisamente el sector de los jóvenes el más familiarizado con la participación tecnológica, el más activo en redes sociales y, en su relación con escuelas e institutos, un sector posiblemente mejor informado acerca de las iniciativas municipales; sin embargo, el planteamiento de las propuestas no parece resultarles atractivo. Por su parte, el concejal entrevistado del Partido Socialista considera que el equipo de gobierno del municipio trató de implantar un modelo de participación que daba mayor importancia a los individuos frente a las asociaciones y que trasladaba el modelo y el impulso político de las protestas del 15-M contra el sistema general de representación política (entrevista $n^{\circ}$ 10). Los partidos políticos de la oposición (Ciudadanos y Partido Popular, específicamente), si bien consideran que la idea de la creación de los Foros locales como órgano de participación individual no es mala, entienden que la participación es baja porque la gente no dispone de la información suficiente, las propuestas son muy generales y hay una instrumentalización política de la participación mediante propuestas y preguntas orientadas en favor del gobierno, cuyo objetivo es crear "un instrumento de marketing político" y una "apariencia de participación" (entrevistas n 10 y 11). El concejal del Partido Popular destaca la necesidad de contar con una profunda cultura democrática para que puedan funcionar las iniciativas de participación porque, de lo contrario, como sucede en el caso de Madrid, "se usa la democracia directa para debilitar la democracia representativa" y existe el riesgo de la "captura de los mecanismos de participación por parte de grupos sociales organizados" (entrevista $n^{\circ} 11$ ). Por su parte, el concejal-presidente del distrito Centro considera que "cualquier problema de la ciudad tiene mayor repercusión pública en el centro de la ciudad, en el que la presión del mercado sobre el espacio público es enorme, y que los canales digitales (Decide Madrid y participación ciudadana) de participación se usan en positivo, mientras que los grupos que quieren ganar influencia ante la opinión pública utilizan los medios de comunicación tradicionales y las redes sociales de forma negativa" (entrevista $n^{\circ} 8$ ). En este sentido, reconoce que Twitter es un instrumento muy eficaz para hacer presión, y que los diferentes actores sociales han aprendido a utilizar los medios de comunicación en favor de sus intereses particulares (llaman a los medios cuando organizan una protesta anti-desahucios, utilizan las redes sociales o buscan aliados para que apoyen propuestas propias) y recurren como medio más efectivo a la relación bilateral directa con el concejal-presidente del distrito. Reconoce que esta relación bilateral, al margen de los canales oficiales de participación, no es justa porque "el más fuerte gana", pero lo 
ve inevitable. Considera, además, que el papel de los actores sociales es cambiante y, en el caso del distrito, las asociaciones de padres y madres empiezan a ser más activas que las asociaciones de vecinos tradicionales, que han estrechado el foco de sus demandas, y hacen propuestas amplias que tienen que ver con el espacio público y el entorno urbano. Así, el desafío es "cómo introducir lo digital en la concertación, puesto que, en temas de cierta complejidad, el resultado debe ser más deliberativo" (entrevista $n^{\circ} 8$ ).

Así, la preferencia por la presión directa a las autoridades del distrito es reconocida por las propias asociaciones de vecinos, que lo ven como la forma más eficaz de ejercer presión en defensa de sus derechos y recelan de los instrumentos participativos formales, en los que su capacidad de influencia y de representación quedó diluida tras la creación de los Foros locales. Esta es una visión compartida por todos los representantes de las asociaciones vecinales entrevistados (entrevistas $n^{\circ} 4,5$ y 7) y confirmada por el personal técnico del Ayuntamiento, para quienes a las asociaciones no les gusta el Foro local porque sus propuestas quedan diluidas entre las de los ciudadanos individuales ("que se preocupan por problemas muy concretos"), y al Foro local no le gusta la plataforma Decide Madrid porque permite la presentación de propuestas en un medio digital que no han sido debatidas ni consensuadas en el Foro (entrevista $n^{\circ} 2$ ).

Por último, se puede tener una perspectiva completa de las preocupaciones de lo institucionalmente representado como el conjunto de los vecinos del distrito Centro si se analizan las quejas y sugerencias presentadas al Ayuntamiento. Para hacerlo, se han analizado los ficheros de quejas y sugerencias generales (excluidas las quejas tributarias) correspondientes a los años 2017, 2018 y 2019. El número de quejas en esos tres años es 186334 desde el 1 de enero de 2017 hasta el 31 de mayo de 2019. De esas quejas, se han extraído las 10274 que corresponden al distrito Centro (el 5,51 \% del total) y se han agrupado utilizando las categorías empleadas por el Ayuntamiento de Madrid, según se expone en la Figura 5. Como puede verse, el grupo de quejas y sugerencias más numeroso es coherente con los principales problemas tratados en los órganos de participación: nuevamente los problemas sobre transporte/movilidad, medio ambiente y espacios públicos centran el grueso de las preocupaciones de los madrileños del distrito Centro. 
Figura 5. Quejas y sugerencias presentadas por los vecinos del distrito Centro (2017-2019)

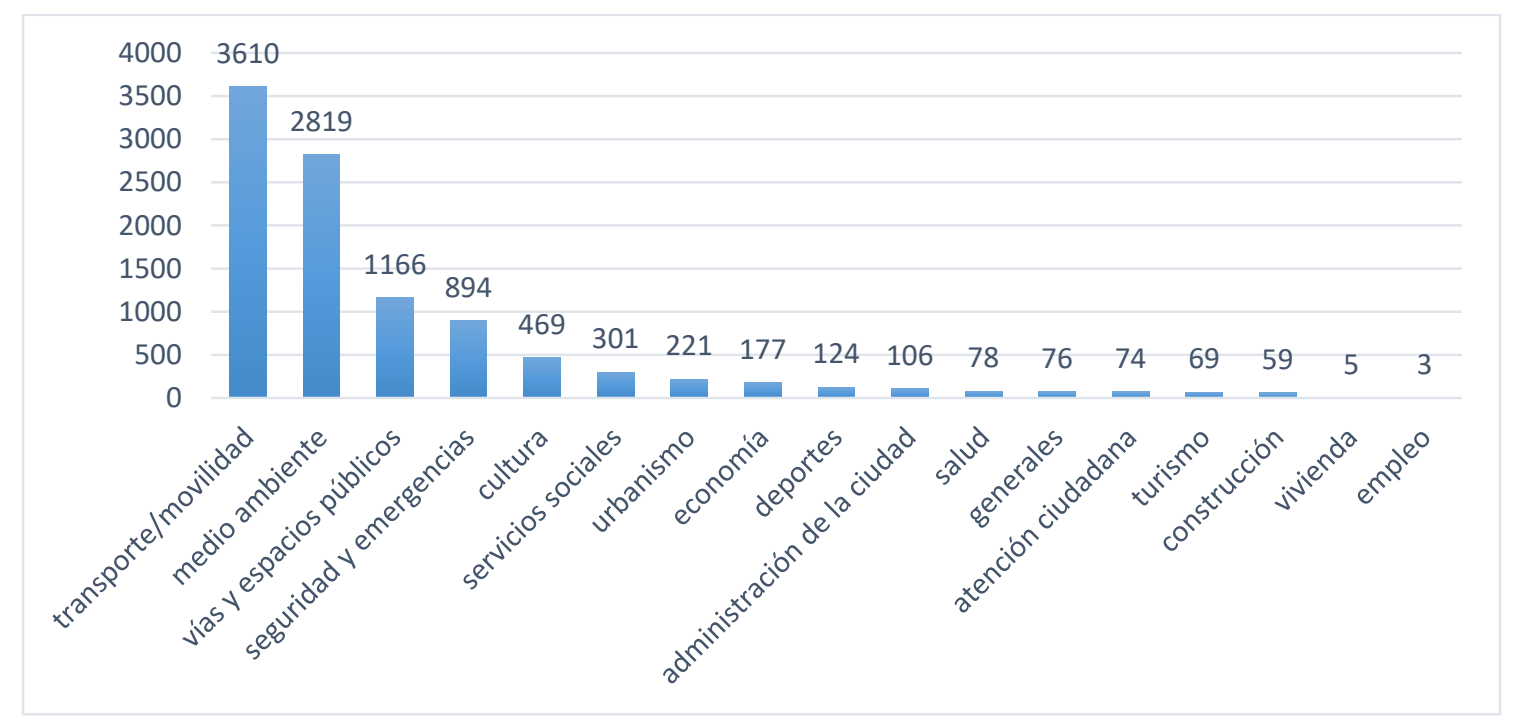

Fuente: elaboración propia a partir del portal web de datos abiertos del Ayuntamiento de Madrid

Una vez identificados los principales problemas del centro urbano a partir del análisis de las propuestas realizadas en los medios presenciales y digitales de participación, resulta interesante contrastarlos con las respuestas obtenidas en las entrevistas en profundidad. Resulta curioso, en primer lugar, que haya cierta identidad temática entre los temas destacados en los ámbitos participativos y lo expresado en las quejas y sugerencias; y, en segundo lugar que, aunque el turismo no aparece destacado como uno de los principales problemas del centro de la ciudad en el Foro local ni en el Pleno del distrito, sí aparece citado en las entrevistas realizadas como uno de los problemas fundamentales por parte de todas las asociaciones de vecinos y todos los grupos políticos. Con todo, ya se ha visto que sí preocupan de forma permanente otros problemas que pueden asociarse, al menos parcialmente, al fenómeno del turismo de masas. En este sentido, junto al turismo, tanto las asociaciones como los concejales de los cuatro grupos políticos, señalan unánimemente la suciedad, el ruido, el ocio nocturno y el encarecimiento del precio de la vivienda debido a los procesos de gentrificación y de transformación de los pisos residenciales en pisos turísticos. Además de estos problemas, alguna asociación de vecinos y el concejal-presidente del distrito destacan la falta de equipamientos públicos (entrevistas 5 y 8), los problemas de seguridad en el barrio de Lavapiés asociados al tráfico de drogas y problemas de integración de población inmigrante (entrevista $\left.n^{\circ} 11\right)$ y problemas de venta ambulante ilegal y ocupaciones de viviendas (entrevistas $n^{\circ} 10$ y 11$)$.

En relación con estos problemas, se reconoce en todos los casos su complejidad y la necesidad de abordarlos desde una perspectiva intergubernamental. Así, el concejal-presidente del distrito 
reconoce un "exceso de expectativas" sobre lo que se podía hacer con las únicas competencias del Ayuntamiento para enfrentar problemas como la transformación del uso residencial de las viviendas a uso turístico o el encarecimiento del precio de las viviendas, y se muestra pesimista con respecto a las posibilidades de implementar algunas medidas como el "Plan Especial de Regulación del uso de Servicios Terciarios en la clase de Hospedaje" aprobado el 27 de marzo de 2019 (entrevista $n^{\circ}$ 8), al que se hizo referencia anteriormente. En el mismo sentido, los concejales de Ciudadanos y del Partido Popular señalan la falta de competencia del Ayuntamiento para frenar por sí solo este problema o el problema del tráfico de drogas, del que no es el único responsable, y señalan la variedad de factores causales de problemas como el del precio de la vivienda que dificultan su solución. En todo caso, sí responsabilizan directamente al Ayuntamiento de los problemas de movilidad y ambientales, como el ruido o la suciedad (entrevistas $n^{\circ} 10$ y 11), mientras que también se lamenta por parte de los concejales del PSOE y de Ciudadanos la tardía reacción regulatoria del gobierno municipal (entrevistas $n^{\circ} 9$ y 10).

En consecuencia, puede decirse que el turismo de masas sí forma parte directa o indirectamente de las preocupaciones de los ciudadanos, sus asociaciones y los partidos políticos. Tanto es así que en 2018 algunas asociaciones de vecinos denunciaron ante el Defensor del Pueblo la permisividad y el fomento por parte de las Administraciones de un modelo de turismo no sostenible que privilegiaba los intereses de los turistas y de la industria del ocio y de hostelería frente a los derechos de los vecinos a descansar y a vivir en un entorno libre de contaminación acústica y atmosférica, y de la inseguridad que causa la transformación de las viviendas residenciales en espacios de alojamiento turístico y de diversión.

En efecto, como bien reconoce el informe del Defensor del Pueblo (2018-2019), el turismo, como actividad beneficiosa (representa el 6,5\% del empleo y del PIB en la Comunidad de Madrid), "debe estar dimensionado y planificado". De lo contrario, el ruido y las actividades de ocio pueden perturbar el descaso de los vecinos, pueden esperarse conflictos entre los usos y horarios de los turistas y los de los residentes habituales, así como un sentimiento de inseguridad derivado de la presencia en edificios residenciales de personas ajenas a la comunidad que disponen de acceso a las zonas comunes de los inmuebles. A medio y largo plazo, la presión del mercado y, en consecuencia, la transformación de las viviendas residenciales en viviendas turísticas puede aumentar el precio de la vivienda y puede terminar expulsando del centro de la ciudad a la población residente al tiempo que se terciariza el centro de la ciudad como ya ha sucedido en otras ciudades. 
Sin embargo, en primer lugar, resulta llamativo que no haya informaciones muy precisas sobre la oferta de viviendas turísticas, por lo que gran parte de la oferta turística está fuera del control administrativo. La Comunidad Autónoma de Madrid, que es la Administración responsable en materia de política turística (a través de la Consejería de Cultura, Turismo y Deportes e, indirectamente, a través de la Consejería de Medio Ambiente y Ordenación del Territorio, en todo lo relativo a urbanismo y ordenación territorial), reconoce en el expediente abierto por el Defensor del Pueblo que no dispone de información sobre la oferta turística real, sino tan solo de las 7982 viviendas de uso turístico que hay en la región de Madrid y que se han inscrito voluntariamente en el Registro de Empresas Turísticas, de las cuales 7778 están en el municipio de Madrid. Ahora bien, para el Ayuntamiento de Madrid, las viviendas de uso turístico han crecido en los últimos años a tasas del 100\% anual en todos los barrios del distrito Centro, mientras que la web Inside Airbnb (que viene a suponer el $80 \%$ del mercado) presentaba un oferta de más de 4800 viviendas en el distrito Centro en 2018, lo que supone el 55\% de toda la oferta de vivienda turística de Madrid, mientras que el propio Defensor del Pueblo calcula la oferta en 16.313 en el conjunto de Madrid (Defensor del pueblo 2018-2019). En cualquier caso, resulta evidente que el desconocimiento de la realidad de este fenómeno dificulta la eficacia de la acción administrativa en materia de inspección y control.

En segundo lugar, se trata de un problema que exige de un esfuerzo de coordinación importante entre las tres Administraciones que operan en el territorio: por un lado, algunos de los principales problemas percibidos como tales por los vecinos (ruido, suciedad, molestias a los vecinos) pueden tener su origen en actividades turísticas o no y, en consecuencia, la Administración responsable puede ser el Ayuntamiento o el gobierno regional. Además, el gobierno de la región es responsable en materia de turismo y otras relacionadas, como el urbanismo y la ordenación territorial, pero la ley que regula las obligaciones y derechos de los propietarios de viviendas urbanas o los arrendamientos (la Ley de Propiedad Horizontal y la Ley de Arrendamientos Urbanos) es responsabilidad del Estado. Sin embargo, el Ayuntamiento de Madrid expresa las dificultades que tiene para realizar labores de inspección por no poder contar con el registro de viviendas de uso turístico del gobierno regional. Aun así, el Ayuntamiento afirma haber inspeccionado, entre agosto de 2018 y noviembre de 2019, 3723 viviendas en el distrito Centro, de las cuales se dedican al alojamiento turístico 729 (Defensor del Pueblo 2018-2019), mientras que la Comunidad de Madrid reconoce haber realizado apenas 58 inspecciones en el período 2014-2018, lo cual es llamativo a la vista de la magnitud del fenómeno. En definitiva, a la falta de un conocimiento aproximado de la dimensión del problema por parte de las Administraciones 
responsables, se suma la ausencia de un diagnóstico preciso sobre las repercusiones de la oferta turística en la vida de los vecinos y en otras políticas (urbanísticas, ambientales, sociales, ...), y una reacción aislada y tardía (en el caso del Ayuntamiento) y prácticamente inexistente (en el caso del gobierno regional) frente a un problema que exige por su propia naturaleza de estrategias y medidas de colaboración intergubernamental.

\section{Disidencias no organizadas}

Esta desconexión entre niveles administrativos que imposibilita la transparencia de estos aspectos no es tenida en cuenta sin embargo por un elevado número de vecinos que defiende sus posiciones críticas en base a otras premisas; que no son, a su vez, entre ellos compartidas. El hecho de que no haya información veraz sobre el número de viviendas sin licencia turística es recibido y expresado por los más críticos como una suerte de no-acción institucional que, sin embargo, quiere contar con ellos en otros momentos no verdaderamente importantes ("esto es un ejemplo perfecto de la no voluntad de los políticos (...) hoy saben lo que quieren y eso no lo quieren saber (...) bien que hacen encuestas y de todo... Es que esto no es algo nuevo, por favor, que llevamos más de diez años con esto... (entrevista $n^{\circ}$ 12)”. La organización de la ciudadanía y la formación de asociaciones ha dinamizado la convivencia vecinal en la última década con mayor o menor participación en los cauces de los anteriores epígrafes, y los ánimos al respecto de sus participantes están muy afectados. Varios de ellos han incorporado estos compromisos como parte de sus acciones vitales en el día a día, construyendo y construyéndose en una cultura organizativa que ha ido tejiendo una malla de concienciación ciudadana que vincula y compromete, en su mayoría, en iniciativas de economía colaborativa al margen de los cauces tratados ("permite una reconexión entre vecinos que no nos conocemos (...) parece mentira, ¿no? No conocía a mis vecinos hasta que me apunté a La Escalera". Entrevista 19). Como un proceso habitual, asociaciones en cierta forma históricas en la lucha contra este fenómeno como "SOS Malasaña", muy implicadas a día de hoy en los cauces formales, han sido el germen de iniciativas particulares que no siempre cristalizan, pero que permiten sentir la gestación de un sentir la ciudad políticamente cada vez más difundido (Mansilla, 2018). Uno de los ejemplos más evidentes de esta conciencia gestante es la cada vez más numerosa acción de visibilizar el descontento en los balcones del distrito Centro mediante rótulos de "SOS Madrid Centro: vecinos en peligro de extinción".

Este tipo de movimientos tienen su origen en lo representado como la "degradación de la vida vecinal". Los vecinos adscritos a este movimiento comparten que el fenómeno de la turistificación 
es un problema para la convivencia por la degradación de lo que representan como calidad de vida, materializada en las quejas que elevan las asociaciones anteriormente citadas en las que algunos participan; aunque es el motivo por ellos más publicitado, no es el único. Este descontento compartido crece con sentires difícilmente trasladables a las actas formales de las instituciones de gobierno pues son, en su mayoría, fenómenos concomitantes agrupados en torno a un fenómeno tan general y difícilmente gestionable administrativamente como la "especulación urbanística" en los términos en los que las reuniones institucionales se desarrollan.

\subsection{Espacios e identidades: los gatos de los madriles}

La crisis de 2008 ha provocado un severo desplazamiento de población en el distrito Centro que ha llevado consigo una reorganización interna económica, social y política. Muchos de los representados por entonces como nuevos vecinos de los barrios de Malasaña y Chueca, especializados en el sector audiovisual, musical o artístico, y del sector servicios en general, perdieron su trabajo. Aquellos que lo conservaron tampoco pudieron hacer frente al vertiginoso incremento del precio del alquiler y se reubicaron gradualmente dentro del distrito Centro, pero al sur de la puerta de Sol; otros grupos fueron expulsados del distrito secuencialmente hacia el barrio de Carabanchel, revitalizada por nuevas propuestas hasta entonces desconocidas en el barrio, y otras zonas de Madrid sur. El fenómeno de la gentrificación que en su día renovó las imágenes de esos dos barrios comenzó a colorear las zonas de Tirso de Molina, las partes alta y baja de Lavapiés y particulares microzonas del Rastro, hasta entonces representados por muchos como nolugares por su imagen mayoritariamente compartida como "de paso". Los vecinos de las zonas de reubicación muestran de hecho su malestar por el incremento general de los precios que, si bien comienzan por la vivienda, afecta expansivamente a los comercios, cafeterías y otros nuevos establecimientos dirigidos a un nuevo público que, en un comportamiento acentuado en el último quinquenio, habita la zona desde hace casi una década. Estos movimientos poblacionales sacuden las imágenes evocadas por las memorias de los habitantes locales figurando un nuevo mundo que deviene en inevitable. Si bien los desacuerdos son explícitos por el ruido y la suciedad, acciones fácilmente retratables en los marcos oficiales, formalmente en los nuevos vecinos traen consigo capital que dinamiza la zona y, entre otras cosas, "trae a más policía por el barrio"; como cualquier hecho social, para unos problemático y para otros un alivio que "permite vivir mejor" en zonas que han sido representadas como "olvidadas por el Ayuntamiento" (entrevistas n 13, 15, 16,18 y 19). 
Los nuevos habitantes no se relacionan de la misma forma que lo hacían los que se presentan como originarios ("ahora yo ya no conozco a nadie... mira, en esa casa nació Ana Belén, aquí vivía uno que fue Alcalde, en todo ese piso vivía una familia de gitanos que éramos muy amigos y ahora... no sé, no sé nada de nadie" entrevista $n^{\circ}$ 13). Con nuevas relaciones sociales por construir y un uso distinto de los espacios públicos, el miedo a lo desconocido suscita desconfianza entre aquellos que recuerdan imágenes doradas de otros madriles. Representaciones ligadas a lo tradicional que evocan las imágenes de una ciudad sostenible y amigable, una ciudad de mercado y de comercio de proximidad que ayuda a crear comunidad y que es, a su vez, potenciada con intereses turísticos hacia sectores internacionales interesados en este tipo de productos; consumidores representados como buscadores de lo auténtico y que aprecian las claves de lo genuino. Es toda una corriente de consumo global que ha cobrado particular importancia para configurar una "hipermodernidad tercermundista" (Friedman, 2001, p. 171) de la que los Estados no pueden permanecer al margen, pues están elaboradas con la jugosa esencia de las "expresiones culturales" que parecen identificar a las comunidades visitadas como lo que son (UNESCO, 2005), así como a sus visitantes por el hecho de conocerlas... antes de que a los verdaderos mensajeros de la globalización se les permitiera visibilizarse, los conflictos identitarios de los madrileños ya operaban constitutivamente en una aventura de diseño en la que historiadores, antropólogos y periodistas han reflexionado sobre las identidades de los madrileños. Se ofrece desorganizadamente su resultado a los miles de turistas que visitan a pie la ciudad de Madrid, y son compartidas por los nuevos inquilinos del centro, como historias identitarias que densifican el suelo que pisan formando comunidades imaginadas con las que turistas y recién llegados creen convivir, en el sentido en que pasan a representar estereotipadamente a los ciudadanos cotidianos y a sus quehaceres y desafíos comunes (Anderson, 1993). Historias de pueblos perseguidos, colectivos marginados o minorías étnicas reivindicando su libertad dibujan con aire mítico una preciosa historia de elementos trágicos que funcionan de forma eficaz para construir la autenticidad de un relato que, así enriquecido, convierte a la identidad local en un producto intercambiable en los circuitos consumistas de estas atribuciones (Appadurai, 1991; Kirshenblatt-Gimblet, 2006). Para la consolidación del producto, las instituciones proyectan de forma ambivalente también la imagen de Madrid en su representación cosmopolita, empleada para participar en estos círculos internacionales dirigidos hacia las posiciones de sujetos que quieran visitar una "capital" y, para ello, se asumen, comparten y potencian los discursos de lo global como propios para hacer de Madrid una capital del mundo globalizado; afectando particularmente a los vecinos del distrito Centro, que dejan constancia en las actas sin embargo 
exclusivamente los efectos mencionados. Para reforzar su cotizada autoctonía, los sujetos que perviven estereotipadamente son re-tradicionalizados mediante la constante revitalización de la imagen de "gatos", a los que las campañas del Ayuntamiento y Comunidad se dirigen en estos últimos años. Se busca un perfil de ciudadano que, inevitablemente, excluye a los que no son relativamente jóvenes, digitalizados, concienciados ecológicamente, emprendedores, estetas y recientes progenitores con hijos jóvenes, y al que se le representa como un "vecino del barrio" que consume en el pequeño comercio y en los mercados de la ciudad (entrevistados $n^{\circ} 12,14$ y 19); argumentos mayoritarios de demandas vitales en los cauces formalizados. El giro estético de los mensajes de publicitarios del Ayuntamiento de la ciudad es visible al incorporar imágenes actualizadas de los valores solidarios a los que hemos hecho referencia como de convivencia y sostenibilidad. Si se trata de lograr que el mensaje institucional llegue a una más amplia audiencia, la construcción capitalizante debe trascender a la historia de unos pocos para incorporar la de los representados como nuevos vecinos. Para ello, no se ha olvidado el Ayuntamiento de incorporar las fiestas musulmanas del Ramadán y del Cordero; del colorido y espectacularizado Holi y otros actos de visibilización de comunidades hinduistas -tanto indias como pakistaníes- no carentes de polémica aquí y en otras ciudades; la celebración del nuevo año chino; los caporales bolivianos, y otras muchas con las que se crean un repertorio en el que los tradicionales gatos, chulapos, majos y flamencos también tienen algo que decir; precisamente más cuanto mayor es el número de extraños que habitan ahora la ciudad. Además, refuerza el aire de tradición revitalizada el hecho de evitar iconos estereotipados desagradables para estos perfiles, por ejemplo, las celebraciones relacionadas con el mundo de los toros que se apartan de las castizas representaciones de las que hacen gala las tiendas de recuerdos y souvenirs ("Yo cuando vengo a Madrid no falto nunca. San Isidro es un clásico", entrevista n 18).

Las acciones del último gobierno municipal han fomentado una deslocalización de la acción de los planes del Ayuntamiento hacia otros distritos y ha respaldado visiblemente "la recuperación de la identidad de los barrios". Como un paquete turístico más, se ofrece una imagen de "identidad de barrio" construida de la mano de espacios y paisajes sin contar con sus protagonistas en tanto que sus vivencias y demandas son sustituidos por el propio espacio, que se muestra y ofrece para construir la identidad social que luego es administrativamente gestionada; pero este tratamiento no es nuevo. El descontento por la presión del crecimiento de la renta de "alquileres no regulados" y su vinculación con los planes de especulación del suelo no son elementos nuevos. Si bien parte de la ciudadanía representa favorablemente esta apuesta, los vecinos del distrito Centro comparten 
la generalizada sensación de que la capital se sirve al turista en bandeja de plata al fomentar unidimensionales consumos hosteleros (entrevistas $n^{\circ} 12,15,16,17$ y 19).

\subsection{Las voces negadas: el otro como intruso}

Es difícil materializar en los actuales cauces formales de participación ciudadana que, si al movimiento interno de reorganización poblacional se le añade el fenómeno de la turistificación canalizado también hacia el distrito Centro, la "sensación de invasión" de "turistas" e "inmigrantes que experimentan sus habitantes; aunque también por "españoles" (entrevistas 13, 17 y 18). La posición atribuida a los nuevos visitantes y vecinos de la figura de extranjero en su papel de visitante, en su sentido más amplio de extraño, es habitualmente representada por los discursos más localistas como la de un intruso que, experimentando la presión social de la saturación del distrito, no atiende ya a nacionalidades para construir y atribuir una posición por nadie deseada. Sin atender a procedencias distintas, es diseñado sobre la base de una procedencia simbólicamente representada como extraña y, por tanto, ubicado fuera de toda frontera de distintos niveles administrativos. El intruso ya no será excluido entonces únicamente por una condición totalizante de extranjero, sino que, también identificado por vivir públicamente de forma distinta provocará su exclusión y, tras la organización de la protesta, se forzará su expulsión.

La cohabitación de sujetos con culturas diversas en un único espacio representado a su vez como lugares distintos por todos ellos, genera en un relativamente pequeño espacio muy diversos ambientes que pueden crear tensiones en la convivencia. Cuando esta situación se produce, cierto sector considera que determinadas prácticas no deberían ser reproducidas, pues suponen para ellos una publicitación de elementos de carácter privado considerada excesiva o inapropiada por algunos de los participantes. Los usos distintos del espacio público son uno de los principales problemas en el choque de la convivencia ("no pueden estar ahí todo el día... ¿no tienen casa o qué? Mañana, tarde y noche... aquí no hay quien viva", entrevista $\left.n^{\circ} 13\right)$. Así, lo construido como lo apropiado en situaciones concretas parece estar particularmente influido por imágenes distintas acerca de lo adecuado en lo público y lo privado, que pueden aparecer minusvaloradas en las actas como una queja común, encubriendo los verdaderos problemas que representa pues, si bien los turistas hacen uso del espacio público en el distrito Centro, lo hacen principalmente mediante el consumo hostelero en los espacios formalmente habilitado para ello; al menos durante el día. Pero otros usuarios aparecen como varados en ciertos lugares públicos donde pasan los días relacionándose con otros compatriotas, amigos o compañeros. Cuestionados ante la posibilidad de poner en práctica vías de inclusión en lo cotidiano, la historia de cualquiera de 
ellos puede asegurar que es la red de contactos y no sólo el repertorio de disposiciones la que permite acceder en términos formales no ya a un trabajo, sino a toda la red pública de prestaciones (entrevistas $n^{\circ} 15$ y 16 ).

Son los inmigrantes en situación irregular los relegados a posiciones de perdedores por la combinación de estos fenómenos. Muchos desconocen que el Ayuntamiento de Madrid no tiene competencia para realizar ningún control sobre la legalidad o ilegalidad de la residencia en territorio español de ninguno de sus vecinos; que pueden acceder a la atención sanitaria en igualdad de condiciones que los españoles regularizados, siempre que lleven empadronados un mínimo tres meses o, en su defecto, que acrediten su situación de vulnerabilidad a través de los servicios sociales. Estos ciudadanos que llegan a un Madrid rompeolas no suelen encontrar la vía para convertirlo en trampolín que les lleve adonde quieren, y quedan encerrados en dinámicas urbanas de exclusión que maltratan y deshumanizan. Por supuesto, no parecen tener ningún tipo de acceso a herramientas de participación ciudadana porque no suelen estar informados de estas dinámicas, o porque creen que no les afectan, o porque sus urgencias vitales pasan por otras acciones (entrevistas 15 y 16). Para dar visibilidad a las posiciones más excluidas del distrito Centro se suman los esfuerzos de varias iniciativas que, inspirados por las acciones previas en la ciudad de Barcelona, fundan en 2016 el "Sindicado de Manteros y Lateros de Madrid", que aspira a una homologación y garantía de los derechos de profesiones invisibilizadas que, por su número creciente en espacios públicos, comienzan a entrar en la agenda política.

Pero no solo la vida de este tipo de vecinos está condicionada por trámites administrativos. La crueldad de la ciudad hace que incluso los nacionales que no son de Madrid, a pesar de "ser de aquí", ocupen posiciones donde Madrid es representado como un espacio hostil invivible que les excluye. Es particularmente en los momentos de más bajo ánimo cuando se asumen estas posiciones por la dureza de la vida en la ciudad con sus adversidades cotidianas y, desde ellas, retoman el discurso de "ser de fuera" al no identificarse con la ciudad, por sólo sentir que Madrid les expulsa (entrevista 12 y 19). Los procesos de construcción identitaria pasan además por procesos de identificación en los que no hay que ser de Madrid para reivindicarse como madrileño ("nací en República Dominicana pero soy de aquí" o "yo llevo aquí toda la vida", entrevistas 17 y 18) y, frente a aquella minoría, el trabajador extranjero que viene a encontrarse un Madrid rompeolas en su acogida y trampolín en su proyección, puede encontrarse con una realidad no tan amable. El cambio de las políticas le afecta severamente sobre el precio de la vivienda, además de encontrarse con accesos restringidos a becas y contratos de trabajo para continuar su estancia por su condición de no-nacional, a pesar de tener su documentación en 
regla. Frente a estos, la no participación en la vida pública de la ciudad de los no-nacionales que viven temporalmente en la ciudad por motivos diversos, parece ubicarles paradójicamente en posiciones más favorables. Aunque la visita está habitualmente relacionada con "turismo" o con "trabajo", "siempre se aprovecha para ver a los amigos" y encontrarte la ciudad mejorada (entrevista 18). Es una situación doblemente ganadora la del propietario jubilado, doblemente inclusiva, al poder circular libremente por una ciudad que en su transformación respeta siempre los intereses de un perfil cosmopolita de propietario-turista que se ve siempre recompensado, a pesar de su no participación formal, al encontrarse "un Madrid cada vez más internacional y moderno, más globalizado" (entrevistas nº 14 y 18).

\section{Conclusiones}

El Ayuntamiento de Madrid ha desarrollado en el período estudiado (2015-2019) diferentes canales de participación, digitales y de naturaleza presencial, que permiten a la ciudadanía debatir, formular propuestas y adoptar decisiones sobre la puesta en marcha de medidas frente a los problemas de su distrito y del conjunto de la ciudad. Sin embargo, estas herramientas participativas han sido puestas en cuestión desde distintos puntos de vista: culturales (falta de una cultura participativa que no favorece la implicación de la ciudadanía o por resistencias en el interior de la organización) o políticas (riesgos de instrumentalización a favor de gobierno municipal y de captura de los espacios participativos por parte de grupos organizados en un contexto de baja participación y representatividad social).

Lo identificado como "falta de cultura participativa" oculta disidencias no organizadas con múltiples causas conscientes de deliberada no-participación ciudadana: los intangibles que los sistemas formalizados de quejas no pueden materializar en su actual dinámica como los ambientes en los que la ciudadanía vive y que condicionan la participación en esta y otras acciones. Este absentismo es reconocido y aireado como el más visible de los rechazos deliberados hacia la institución.

Analizados los resultados de los procesos participativos, los principales problemas identificados por los ciudadanos del distrito Centro están relacionados con la mejora de los espacios públicos, las cuestiones ambientales y el transporte y la movilidad en el interior de la ciudad.

El turismo no aparece expresamente como un problema sentido por la población. Sin embargo, del análisis pormenorizado de los problemas expresados y de las entrevistas realizadas con representantes del Ayuntamiento y de los actores sociales y políticos, se desprende que los efectos 
del turismo se dejan sentir con extrema crudeza en los problemas del ruido, la suciedad, las actividades molestas del ocio nocturno, la transformación de la vivienda residencial en vivienda turística y, al cabo, el incremento de los precios de la vivienda para la población permanente.

La "turistificación" como derivación negativa del turismo de masas está fuera del control de las autoridades administrativas: no hay un diagnóstico preciso de la dimensión del problema ni actividades inspectoras o de control suficientes y sistemáticas; no hay estudios que empleen indicadores de la transformación del tejido social y empresarial del centro urbano ni de las repercusiones de este fenómeno en otras políticas; y no hay colaboración efectiva entre Administraciones para dar respuestas conjuntas al problema.

Los esfuerzos de Ayuntamiento y la Comunidad de Madrid en la construcción identitaria de la ciudad por dar una imagen más cosmopolita, actual o globalizada a la ciudad de Madrid, es identificada como parte del fenómeno de capitalización de la sociedad, generando disensos entre los grupos de vecinos que encuentran en estas posiciones los puntos de mayor desencuentro.

Las herramientas participativas no son paradójicamente empleadas por aquellos vecinos que más se verían afectados por los resultados de las propuestas al promoverse un fuerte vínculo entre el fenómeno de la turistificación y las operaciones urbanísticas de la ciudad compartida por los vecinos, que deviene en un desentendimiento de propuestas maximalistas relacionadas con tratamientos urbanísticos de la ciudad.

Agradecimientos: Este artículo se ha elaborado en el contexto del proyecto PAITUR-Ciudad (https://www.ucm.es/paitur-ciudad/), proyecto correspondiente a la convocatoria 2016 del Programa Estatal de Investigación, Desarrollo e Innovación Orientada a los Retos de la Sociedad (CSO2016-75470-R). Agradecemos la colaboración de todas las personas entrevistadas, que se relacionan al final del trabajo.

Declaración responsable: Las/os autoras/es declaran que no existe ningún conflicto de interés con relación a la publicación de este artículo. El planteamiento del estudio, la definición de su objeto de estudio, la metodología y las conclusiones del artículo son fruto del trabajo conjunto de los tres autores. Además de este trabajo colectivo, cada uno de los autores ha desarrollado con mayor profundidad algunas de las partes del estudio. Específicamente, César Polo ha analizado en el epígrafe 4 los planes de intervención territorial del Ayuntamiento de Madrid; José M. Ruano se ha centrado en el epígrafe 5, referido a la "voz de la ciudad organizada; y Eduardo Iglesias ha trabajado el epígrafe 6 sobre "disidencias no organizadas". 


\section{Bibliografía}

Abler, R., Adams, J., \& Gould, P. (1972). Spatial organization. The Geographer's View of the World. London: Prentice Hall International.

Agger, A., \& B. Damgaard (2018). Interactive Policy Processes. Scandinavian Journal of Public Administration, 22(3), 89-108.

Anderson, B. (1993). Comunidades imaginadas. Reflexiones sobre el origen y la difusión del nacionalismo. Mexico: Fondo de Cultura Económica.

Appadurai, A. (1991). Introducción. Las mercancías y la políitca del valor. In A. Appadurai (Ed.), La vida social de las cosas. Perspectiva cultural de las mercancías (pp. 17-89). Mexico: Grijalbo/Consejo nacional de para la cultura y las artes.

Augé, M. (2009). Los no lugares: espacios del anonimato: Antropología sobre modernidad. Barcelona: Ed. Gedisa

Bonsón, E., Royo, S., \& Ratkai, M. (2015). Citizens' engagement on local governments' Facebook sites. An empirical analysis: The impact of different media and content types in Western Europe. Government Information Quarterly, 32, 52-62. hitps://doi.org/10.1016/j.giq.2014.11.001

Borja. J. (2003). La ciudad conquistada. Madrid: Alianza.

Cañas, J. (2017, August 28). Dimite el vicario de Ceuta por permitir entrar en una iglesia al dios hindú Ganesh. El País. Retrieved from https://elpais.com/politica/2017/08/28/diario_de_espana/1503948959_186534.html

Chebel d'Appollonia, A. (1998). Los racismos cotidianos. Barcelona: Bellaterra.

Clifford, J. (2009). Dilemas de la cultura. Antropología, literatura y arte en la perspectiva posmoderna. Barcelona: Gedisa Editorial

Duch, L. (2002) Antropología de la vida cotidiana I. Simbolismo y salud. Madrid: Trotta.

Falleth, E. I., Hanssen G. S., \& Saglie, I.L. (2010). Challenges to Democracy in Market-Oriented Urban Planning in Norway. European Planning Studies, 18(5), 737-753

Friedman, J. (2001). Identidad cultural y proceso global. Buenos Aires: Amorrortu.

Friedman, J. (2003) Los liberales del champagne y las nuevas clases peligrosas: reconfiguraciones de clase, identidad y producción cultural. In García García \& Barañano (Coords.), Culturas en 
contacto. Encuentros y desencuentros (pp. 161-197). Madrid: Ministerio de Eduación, Cultura y Deporte.

Hertting, N., \& Klijn, E.-H. (2018) Institutionalization of Local Participatory Governance in France, the Netherlands, and Sweden: Three Arguments Reconsidered. In N. Hertting \& C. Kugelberg (Eds.), Local Participatory Governance and Representative Democracy. Institutional Dilemmas in European Cities (pp. 168-194). New York: Routledge.

Innes, J.E., \& Booher, D.E. (2003): Collaborative Policymaking: Governance through Dialogue, In Hajer, M.A. and H. Wagenaar (Eds.), Deliberative Policy Analysis: Understanding Governance in the Network Society. Cambridge: Cambridge University Press.

Kirshenblatt-Gimblett, B. (2006). World Heritage and Cultural Economics, Museum Frictions: Public Cultures/Global Transformations.

Klausen, J.E., \& Sweeting, D. (2005). Legitimacy and Community Involvement in Governance. In M. Haus, H. Heinelt \& M. Stewart (Eds.) Urban Governance and Democracy (pp. 214-233). London: Routledge.

Lahire, B. (2004). El hombre plural: los resortes de la acción. Barcelona: Bellaterra.

Lefèbvre, H. (1978). El Derecho a la ciudad. Barcelona: Capitán Swing.

Lidén, G., \& Larsson, A.O. (2016). From 1.0 to 2.0: Swedish municipalities online. Journal of Information Technology \& Politics, 13(4), 339-351.

Lijphardt, A. (2012). Pattern of Democracy: Government forms and Performance in Thirty-Six Countries. New Haven, CT: Yale University Press.

Mansilla López, J.A. (2018). Vecinos en peligro de extinción. Turismo urbano, movimientos sociales y exclusión socioespacial en Barcelona. Pasos: Revista de Turismo y Patrimonio Cultural, 16(2) 279-296

Newig, J., Pahl-Wostl, C., \& Sigel, K. (2005). The Role of Public Participation in Managing Uncertainty in the Implementation of the Water Framework Directive. European Environment, 15, 333-343.

Peris D. (2014). El caso Triball en números. 1,2,3. Abandono, especulación, expulsión: gentrificación. Contested Cities (Working Paper Series). Retrieved from https://docplayer.es/12283852-Working-paper-series-contested_cities.html

Ríos, L. (2001). La centralidad urbana, In Carrión, F. (ed.): La ciudad construida. Quito: FLACSO. 
Rogers, E., Sert, J., \& Tyrwhitt, J. (1955). Centros para la vida de la comunidad, en el Corazón de la Ciudad. Por una vida más humana de la comunidad. Barcelona: CIAM 8, Hoddesdon \& Hoepli. Ruano, J. M. (2010). Contra la participación: discurso y realidad de las experiencias de participación ciudadana. Política y Sociedad, 47(3), 93-108.

Ruano, J. M. (2019). Actors, Aims and Challenges of Local Strategic Planning in Spain. In C. Hintea, M. Profiroiu, T. Constantin \& C. Tudor (Eds.), Strategic Planning in Local Communities. A Cross-National Study of 7 Countries. London: Palgrave Macmillan.

Sayas, A. (2011). La doble ausencia: de las ilusiones del emigrado a los padecimientos del inmigrado. Barcelona: Anthropos.

Skelcher, C., E-H. Klijn, D Kübler, E. Sørensen \& H. Sullivan (2011). Explaining the Democratic Anchorage of Governance Networks. Administrative Theory and Praxis 22(1), 7-38.

Stolcke, V. (1995). Talking culture: New Boundaries, New Rethorics of exclusion in Europe. Current Anthropology, 36(1), 1-24

Troitiño, M.A. (2003). La protección, recuperación y revitalización funcional de los centros históricos. Ciudades, arquitectura y espacio urbano. Almería: Instituto de Estudios Socioeconómico de Cajamar.

\section{Fuentes documentales}

Ayuntamiento de Madrid (2009). Planes de Barrio del Distrito Centro. Retrieved from https://www.madrid.es/portales/munimadrid/es/Inicio/El-

Ayuntamiento/Centro/Participacion-ciudadana/Planes-de-barrio-del-distrito-

Centro/?vgnextfmt=default\&vgnextoid=3cf76c15a0f99410VgnVCM1000000b205aOaRCRD\&vgn extchannel=d7320a28e4e83310VgnVCM100000171f5aOaRCRD

Ayuntamiento de Madrid (2012). Plan Estratégico de Turismo 2012-2015: Retrieved from https://www.ucm.es/data/cont/media/www/pag99801/Plan\%20Estrat\%C3\%A9gico\%20de\%20Turismo\%202012-2105.pdf

Ayuntamiento de Madrid (2017). Análisis del Impacto de las viviendas de uso turístico en el Distrito Centro de Madrid. Retrieved from

https://www.madrid.es/UnidadesDescentralizadas/UDCMedios/noticias/2017/05Mayo/05vier nes/Notasprensa/ficheros/Informe_final_5_mayo\%20vivendas\%20uso\%20tur\%C3\%ADstico\%20( 1).pdf 
Ayuntamiento de Madrid (2017b). Encuesta de calidad de vida y satisfacción con los servicios públicos de la ciudad de Madrid. Distrito Centro. Retrieved from

https://www.madrid.es/UnidadesDescentralizadas/Calidad/Observatorio_Ciudad/O6_S_Percep cion/EncuestasCalidad/EncuestaMadrides/ficheros/2017/Informesdistritoadistrito/Centro2017.p $\underline{\text { df }}$

Ayuntamiento de Madrid (2019a). Área de información estadística, Retrieved from https://www.madrid.es/portales/munimadrid/es/Inicio/El-Ayuntamiento/Estadistica/Areasde-informacion-estadistica/Areas-de-informacionestadistica/?vgnextfmt=default\&vgnextoid=9023c9faOb23a210VgnVCM2000000c205aOaRCRD \&vgnextchannel=b65ef78526674210VgnVCM1000000b205aOaRCRD

Ayuntamiento de Madrid (2019b). Decide Madrid. Retrieved from https://decide.madrid.es/ Ayuntamiento de Madrid (2019c). Quejas y sugerencias (2017-2019), Portal de Datos abierto Retrieved from

https://datos.madrid.es/portal/site/egob/menuitem.c05c1f754a33a9fbe4b2e4b284f1a5a0/?v gnextoid=20761a5b278c4510VgnVCM2000001f4a900aRCRD\&vgnextchannel=374512b9ace9f3 10VgnVCM100000171f5aOaRCRD\&reloadCaptcha=true

Ayuntamiento de Madrid (2019d). Turismo Madrid. Retrieved from

http://turismomadrid.es/es/descubre/madrid/de-inter\%C3\%A9s/5098-triball-madrid.html

Ayuntamiento de Madrid (2019e). Plan zonal específico de la Zona de Protección Acústica Especial del distrito Centro. Retrieved from http://www.madrid.es/portales/munimadrid/es/Inicio/Medioambiente/Publicaciones/Zona-de-Proteccion-Acustica-Especial-del-distrito-Centro-AprobacionDefinitiva-de-la-modificacion-de-la-normativa-del-Plan-Zonal-Especifico$\underline{\text { ?vgnextfmt=default\&vgnextoid }=4 f c 4 f 67639356310 \mathrm{VgnVCM} 2000000 \text { c205aOaRCRD\&vgnextchan }}$ nel=f6ff79ed268fe410VgnVCM1000000b205aOaRCRD

Ayuntamiento de Madrid (2019f). Planes Integrales de Barrio (PIBA). Centro. Retrieved from https://transparencia.madrid.es/UnidadesDescentralizadas/UDGParticipacionCiudadana/Fo ndo_Reequilibrio_Territorial/Folleto_Centro/PIBAs_Centro_Info-2019.pdf

Ayuntamiento de Madrid (2019g). Estudio sociodemográfico de los barrios de Madrid ligado a los Planes Integrales de Barrio (PIBA). Retrieved from

https://transparencia.madrid.es/UnidadesDescentralizadas/UDGParticipacionCiudadana/Publica ciones_Fondo_Documental/Estudio_Sociologico_Barrios_PIBA/Estudio_PIBA_2019_I.pdf 
Ayuntamiento de Madrid (2019h). Plan Especial de Regulación del Uso de Servicios Terciarios en la Clase de Hospedaje. Retrieved from

https://transparencia.madrid.es/portales/transparencia/es/Medio-ambiente-y-

urbanismo/Urbanismo/Planeamiento-urbanistico/Plan-Especial-de-regulacion-del-uso-de-servicios-

terciarios-en-la-clase-de-

hospedaje/?vgnextfmt=default\&vgnextoid=b71cbc8d3c9f4610VgnVCM1000001d4a900aRCRD\& $\underline{\text { vgnextchannel=eae9508929a56510VgnVCM1000008a4a900aRCRD }}$

Ayuntamiento de Madrid (2019i). Encuesta de calidad de vida y satisfacción con los servicios públicos de la ciudad de Madrid. Retrieved from

https://www.madrid.es/portales/munimadrid/es/Inicio/El-Ayuntamiento/Calidad-y-

Evaluacion/Percepcion-Ciudadana/Edicion-

2019/?vgnextfmt=default\&vgnextoid=7d062d7c2bd6a610VgnVCM2000001f4a900aRCRD\&vgn extchannel=f22ff49c4495d310VgnVCM2000000c205aOaRCRD

Comisión Nacional de los Mercados y la Competencia [CNMC] (2018). Estudio sobre la Regulación de las Viviendas de Uso Turístico en España E/CNMC/003/18. Retrieved from https://www.cnmc.es/sites/default/files/2133063_1.pdf

Comunidad de Madrid (2016-2019) Estrategia de Turismo (2016-2019). Retrieved from https://www.ucm.es/data/cont/media/www/pag-99801/Estrategia\%20Turismo\%2020162019.PDF

Defensor del Pueblo (2018-2019). Reclamación de la Asociación de Vecinos Las Cavas, expediente 18004247. Madrid: Defensor del Pueblo.

EXCELTUR (2018). Estudio sobre el empleo en el sector turístico español. Retrieved from https://www.exceltur.org/wp-content/uploads/2018/04/ESTUDIO-EMPLEO-SECTORTURISTICO-EXCELTUR.pdf

Organización Mundial del Turismo (2018). 'Overtourism'? Understanding and Managing Urban Tourism Growth beyond Perceptions. Centre of Expertise Leisure, Tourism \& Hospitality; NHTV Breda University of Applied Sciences; and NHL Stenden University of Applied Sciences.

Naciones Unidas (2015). Objetivos de desarrollo sostenible. Retrieved from https://www.un.org/sustainabledevelopment/es/cities/

UNESCO (2005). Convención sobre la protección y la promoción de la diversidad de las expresiones culturales. Paris: UNESCO. 


\section{Anexo I. Entrevistas semiestructuradas a representantes políticos, vecinales y burocráticos}

6 de mayo de 2019

1. José María Becerra (Jefe del Servicio de Participación Sectorial)

2. Lucrecia Adeva (Subdirectora General de Participación Ciudadana y Voluntariado)

7 de mayo de 2019

3. Gregorio Planchuelo (Director General de Participación Ciudadana)

Borja Prieto (Director del Servicio de Extensión Institucional)

Raquel Muros (Consejera de la Dirección General de Participación Ciudadana)

4. Ma Jesús Gallego (miembro del equipo de mantenimiento del portal de datos abiertos)

Enrique Crespo (Jefe del Servicio de Acceso a la Información)

5. Manuel Osuna (Presidente de la Asociación de Vecinos La Corrala)

6. Saturnino Vera (Presidente de la Asociación de Vecinos Las Cavas)

8 de mayo de 2019

7. Yago Bermejo (Director de Participalab Madrid)

10 de mayo de 2019

8. Ángeles Rodríguez (Presidenta de la Asociación de Vecinos de Malasaña)

16 de mayo de 2019

9. Jorge García Castaño (Delegado del Área de Gobierno de Economía y Hacienda, y Presidente del Distrito Centro)

10. Pedro Barrero (Concejal del Grupo Municipal Socialista PSOE)

11. Bosco Labrado (Concejal del Grupo Municipal Ciudadanos CS)

17 de mayo de 2019

12. Percival Manglano (Concejal del Grupo Municipal del Partido Popular PP) 


\section{Anexo II. Entrevistas abiertas realizadas a vecinos del distrito Centro}

19 de marzo de 2019

13. Marta Iglesias. Médico. Cuenca, 33 años. Vecina de La Latina, usuaria de huerto urbano, Plaza de la Cebada y espacio ciudadano de Almendro 3.

21 de marzo de 2019

14. Mercedes Sánchez Sánchez. Pensionista. Madrid, 81 años. Viuda, vecina de Lavapiés "desde que recuerda".

13 de abril de 2019

15. José Cortez. Empresario hostelero. Madrid, 44 años. Vecino de Malasaña cuyos negocios están "por el centro y el barrio de Salamanca".

14 de abril de 2019

16. Seila Keita. "Mantero" (no le gusta denominarse así). Senegal, 31 años. Vecino de Lavapiés. Pescador en Senegal, participa habitualmente de la vida pública "del barrio". Vive en España desde hace 2 años.

14 de abril de 2019

17. Deo Impala. Pastelero. Senegal, 33 años. Vecino de Embajadores. Vive en España desde hace 5 años. Comenzó a moverse en círculos de manteros y hace 2 años consiguió "permiso de trabajo y un contrato fijo gracias a un amigo".

15 de abril de 2019

18. Jorge Danilo Suárez. Peluquero. República Dominicana, 29 años. Vecino de Villaverde. Trabaja como peluquero en el barrio de Lavapiés. Vino a Madrid con sus padres hace 21 años.

3 de mayo de 2019

19. Robert D. Spiegel. Empresario tecnológico. México, nacionalizado español. 65 años. Vive en Madrid en invierno y primavera, y en California el resto del año. Propietario de un piso en el barrio de la Latina, es padre de 2 hijas; una de ellas, "muy activista", vive en Madrid. 4 de mayo de 2019

20. Florencia Sexto. Monja seglar. Valladolid, 39 años. Vive en Madrid central desde hace 4 años. Participa en redes de economía colaborativa e imparte docencia en el campo de la innovación social. 